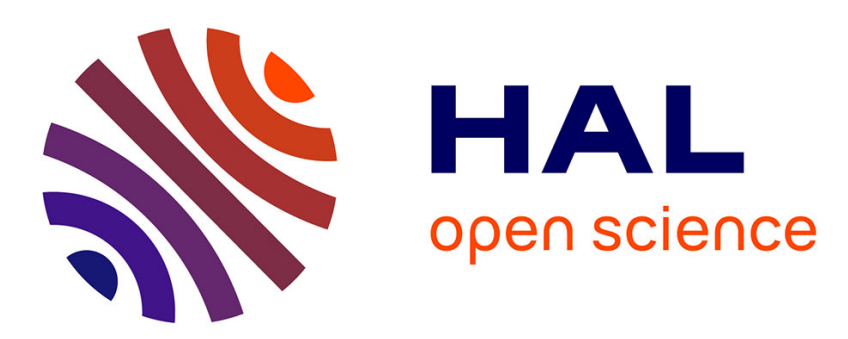

\title{
Use of a non additive GC-PPC-SAFT equation of state to model hydrogen solubility in oxygenated organic compounds
}

Thi-Kim-Hoang Trinh, Jean-Philippe Passarello, Jean-Charles de Hemptinne, Rafael Lugo

\section{To cite this version:}

Thi-Kim-Hoang Trinh, Jean-Philippe Passarello, Jean-Charles de Hemptinne, Rafael Lugo. Use of a non additive GC-PPC-SAFT equation of state to model hydrogen solubility in oxygenated organic compounds. Fluid Phase Equilibria, 2016, 429, pp.177 - 195. 10.1016/j.fluid.2016.08.003 . hal01449587

\section{HAL Id: hal-01449587 \\ https://hal.science/hal-01449587}

Submitted on 30 Jan 2017

HAL is a multi-disciplinary open access archive for the deposit and dissemination of scientific research documents, whether they are published or not. The documents may come from teaching and research institutions in France or abroad, or from public or private research centers.
L'archive ouverte pluridisciplinaire HAL, est destinée au dépôt et à la diffusion de documents scientifiques de niveau recherche, publiés ou non, émanant des établissements d'enseignement et de recherche français ou étrangers, des laboratoires publics ou privés. 


\title{
USE OF A NON ADDITIVE GC-PPC-SAFT EQUATION OF STATE TO MODEL HYDROGEN SOLUBILITY IN OXYGENATED ORGANIC COMPOUNDS
}

Thi-Kim-Hoang TRINH ${ }^{a, b}$, Jean-Philippe PASSARELLO ${ }^{b,{ }^{*}, J e a n-C h a r l e s ~ D E ~ H E M P T I N N E ~}{ }^{a}$, Rafael LUGO

${ }^{a}$ IFP Energies nouvelles, 1 et 4 avenue de Bois-Préau, 92852 Rueil-Malmaison, France

${ }^{\mathrm{b}}$ Laboratoire de Science des Procédés et des Matériaux (LSPM), Université Paris 13, CNRS,

99 avenue Jean-Baptiste Clément, 93430 Villetaneuse, France

*Corresponding author

E-mail address: jean-philippe.passarello@1spm.cnrs.fr (Jean-Philippe Passarello)

Tel : +33149403406

Keywords : PC-SAFT, group contribution method, hydrogen, oxygenated compound, nonadditive

\begin{abstract}
The equation of state based on the Group Contribution - Polar Perturbed Chain Statistical Associating Fluid Theory (GC-PPC-SAFT), which is PC-SAFT combined with the group contribution proposed by Tamouza et al., Fluid Phase Equilib. 2004;222-223:67-76 and a polar term developed by Nguyen Huynh et al., Fluid Phase Equilib. 2008;264(1-2):62-75, is employed here to model the solubility of hydrogen in oxygenated compounds mixtures such as alcohols, ethers, diols, aldehydes. Our analysis shows that in such systems, the gas solubility may be driven by available volume effects. For this reason, a modified version of this equation of state taking into account non-additive segment diameters, is used in this work.

Systematic tests are performed on binary mixtures and a predictive scheme is proposed. A correlation based on the group contribution method is also suggested as a predictive way to determine the non-additive parameter $\left(\mathrm{l}_{\mathrm{ij}}\right)$. Correlations and predictions are qualitatively and quantitatively satisfactory. The deviations are within the experimental uncertainty $(\sim 10 \%)$.
\end{abstract}




\section{Introduction}

The presence of oxygenated compounds[1], [2] in biomass feeds (e.g. alcohols, aldehydes, acids, esters, ethers,...), makes that several major issues must be overcome before it can be used as a fuel, such as a low LHV (lower heating value), high viscosity or chemical instability[3], [4]. A possible way of removing oxygen[5] consists in using a hydrotreatment unit operating at high pressure and temperature[6] in presence of hydrogen $(\mathrm{P}=7$ to $20 \mathrm{MPa}, \mathrm{T}=$ $573.15 \mathrm{~K}$ to $723.15 \mathrm{~K}$ ). Describing the solubility of hydrogen in these oxygenated solvents is an important step in the design of the process. Several thermodynamic models which allow calculation of hydrogen/hydrocarbons phase equilibrium for conventional hydrotreating processes exist. Typical examples are the Grayson Streed method (GS)[7], the cubic equations of state (eos) like Soave - Redlich - Kwong (SRK) and Peng Robinson (PR)[8]. GS doesn't require any adjustable parameter which makes it fully predictive, but is only adapted to hydrocarbon solvents. SRK and PR may be used with an adequate binary interaction parameter, but it is often strongly temperature dependent and requires data for regression. Predictive approaches with cubic eos have been developed, but these also are limited to hydrocarbon solvents[9], [10].The Predictive SRK (PSRK) eos[11] may also be used, but the quality of the results vary considerably depending on the feed or temperature range. Some authors used the different version of the Statistical Associating Fluid Theory equation of state (SAFT EoS) to predict the solubility of hydrogen in hydrocarbons[12], [13]. However, because of the complexity of biomass feeds (the presence of water and a large variety of oxygenated compounds), there is no currently well-defined thermodynamic approach to predict the behavior of these systems.

In the last decade, our research group has developed a group contribution (GC) method[14] combined with a version of the SAFT EoS to predict the fluid-phase equilibrium of systems of interest in the petroleum industry. Satisfactory results are obtained for phase equilibrium calculations of systems containing n-alkanes, n-alcohols, aromatic compounds and alkyl esters, including small molecules like $\mathrm{CO}_{2}, \mathrm{NH}_{3}, \mathrm{CH}_{4}[15]-[19]$. In this paper, the problem of the hydrogen solubility in oxygen-bearing solvents is addressed using a version of GC-SAFT called GC-PPC-SAFT[20]. The prediction of hydrogen solubility (i.e. Henry's constant) using this model showshigh deviations between the experimental data and the predicted values. Regressing energy binary interaction parameter on available data yields negative values for $\mathrm{k}_{\mathrm{ij}}$. 
Negative values cannot be explained by the Hudson and McCoubrey formula based solely on the London -dispersion interaction i.e. assuming that attractive energy of the model is mainly or purely dispersive. As explained by Haslam et al[20] negative $\mathrm{k}_{\mathrm{ij}}$ may be obtained if polar interaction are included in the cross energy parameter. However, in our model GC-PPC-SAFT polar interaction are explicitly taken into account by specific terms in the model. Energy is assumed purely dispersive and thus negative $\mathrm{k}_{\mathrm{ij}}$ values are non-physical in our approach. This is why in this paper, another way is explored introducing a repulsive correction i.e. a binary parameter on diameters (non additive systems). But GC-SAFT cannot be used as it is. Indeed, SAFT equation of state was obtained by using perturbation techniques that generally assumes the reference part as repulsive. This would lead to deal with non-additive hard chains as reference fluid in the EOS for which little is known. Rather than starting from the very beginning with the development of a new equation of state, we based previous work[21], [22]

This paper consists of three parts: first, the description of the model that we use to predict the hydrogen solubility in oxygenated solvents. Second, the analysis of the use of predictive binary interaction parameter $\mathrm{k}_{\mathrm{ij}}$ for the computation of these systems. The next section will explain the reason that led us to develop a non-additive segment diameter approach (with the non-additive parameter $l_{\mathrm{ij}}$ ) in GC-PPC-SAFT and a brief explanation of the model development (for more details see our previous paper). Finally, the results of prediction and correlation of this new parameter are shown and discussed.

\section{GC-PPC-SAFT Equation of State}

\subsection{Model description}

The GC-PPC-SAFT model, namely Group Contribution - Polar Perturbed Chain Statistical Associating Fluid Theory, is the combination of PPC-SAFT[23] with the GC[14] concept in order to determine the three parameters $\varepsilon / \mathrm{k}, \sigma$ and $\mathrm{m}$. This equation is presented as a sum of Helmholtz energy terms at given temperature, volume and composition:

$$
A^{\text {res }}=\left(m A^{h s}+A^{\text {chain }}\right)+A^{d i s p}+A^{a s s o c}+A^{\text {multi-polar }}
$$


Where the first terms (i.e. excluding $\mathrm{A}^{\text {multi-polar }}$ ) is exactly the PC-SAFT EoS by Gross and Sadowski[24]. The reference term $A^{\text {hs }}$ is based on the hard sphere theory of Boublik[25] and Mansoori[26].

The term $\mathrm{A}^{\text {chain }}$ describes the formation of the molecular chain, developed with the assumption of infinite association strength.

The sum $\left(\mathrm{mA}^{\mathrm{hs}}+\mathrm{A}^{\text {chain }}\right)$ is the reference term of the PC-SAFT model. The London-type attractive interactions between segments (dispersive interactions) are taken into account through the second order perturbation theory of Barker and Henderson applied to chain molecules.

These averages involve three parameters: the dispersion energy between two segments: $\varepsilon_{\mathrm{ij}}$, the diameter of segment $\sigma_{\mathrm{ij}}$ and the chain length $\mathrm{m}_{\mathrm{i}}$. Here, $\varepsilon_{\mathrm{ij}}$ is defined as:

$$
\varepsilon_{i j}=\left(1-k_{i j}\right) \sqrt{\varepsilon_{i} \varepsilon_{j}}
$$

In the original rules, the parameter $\mathrm{k}_{\mathrm{ij}}$ is zero; this parameter allows to take into account the deviations to the Lorentz-Berthelot rule due to dispersive interactions between two molecules of different types.

However, to improve the predictive ability of the model, it was found necessary under certain conditions to use non-zero parameters $\mathrm{k}_{\mathrm{ij}}$. Nguyen Huynh et al.[15] proposed to calculate the $\mathrm{k}_{\mathrm{ij}}$ parameters by using a relation established by Hudson and McCoubrey[19] based on the dispersive interaction theory of London et al.[27] and semi-empirically modified by introducing an adjustable parameter for each component. The expression is written as follows:

$$
1-k_{i j}=\frac{2 \sqrt{J_{i} J_{j}}}{\left(J_{i}+J_{j}\right)}
$$

where $\mathrm{J}_{\mathrm{i}}$ and $\mathrm{J}_{\mathrm{j}}$ are the pseudo-ionization energies of molecules $i$ and $j$ which are calculated by group contribution (Equation 18). These are adjustable semi empirical parameters. Note that this approach implies that the $\mathrm{k}_{\mathrm{ij}}$ values are positive. This is important in view of the observation 
made below regarding hydrogen solubility in oxygenated compounds (see the next section for more details).

For the cross diameters $\sigma_{i j}$, the combining rule is :

$$
\sigma_{i j}=\frac{\sigma_{i}+\sigma_{j}}{2}
$$

Spheres that obey the relation between diameters given above are called additive; there is also a modified version of this rule involving a binary parameter $\mathrm{l}_{\mathrm{ij}}$ (in which case the spheres are called non-additive). Some authors (Nguyen T.B. et al.[28], Sadowski et al.[28], [29],...) used Equation (11) corrected with (1- $1_{\mathrm{ij}}$ ) with the purpose to adjust repulsive forces. However, it appears that in the original PC-SAFT this correction only affects the dispersion term and not the repulsive and chain term : it enters into Equation (6) in exactly the same way as the $\mathrm{k}_{\mathrm{ij}}$ parameter. It is better to develop a term in the rigorous way that takes into account the non-additivity of the diameters so that the physical effect be correctly represented.

In section 3, we will give brief explanations how our model was modified to take into account the non-additive interactions between chains in accordance with the thermodynamic perturbation theory.

The contribution $\mathrm{A}^{\text {assoc }}$ (associative term) takes into account the quasi-chemical interactions due to localized attractions, such as hydrogen bonds and charge transfer at short distance (donor-acceptor

The term $\mathrm{A}^{\text {multi-polar }}$ describes the polarity of segments (dipole moment $\mu$ and quadrupole moment Q) and was proposed by Nguyen-Huynh[15] based on the theory of Gubbins and Twu[25] for spherical molecules and the segment approach of Jog and Chapman[26] for chain molecules. This term involves the polar moments (either dipole or quadrupole) and a new parameter which is the polar fraction $\mathrm{x}_{\mathrm{p}}[30]$.

\subsection{Group contribution parameterization of the PPC-SAFT model}

\section{a. Average chain parameters}


These three parameters can either be determined for each molecule or be calculated by group contribution. In order to improve the predictive ability of the model, we used a group contribution method. This is usually done by reducing the number of necessary parameters and by determining parameters that we can use for a greater number of molecules.

Any molecule in SAFT is characterized by at least three parameters $(\sigma, \varepsilon$ and $\mathrm{m})$. Tamouza et al.[14] proposed a method for calculating the parameters of the molecule by using group parameters that are reused here. We have:

$$
\begin{gathered}
\varepsilon_{\text {molecule }}=\sqrt{\left.\sum_{i=1}^{\text {ngroups }} n_{i}\right)} \sum_{i}^{n_{i} \text { groups }} \\
\sigma_{\text {molecule }}=\frac{\sum_{i=1}^{\text {ngroups }} n_{i} \sigma_{i}}{\sum_{i=1}^{\text {ngroups }} n_{i}} \\
m_{\text {molecule }}=\sum_{i=1}^{n g r o u p s} n_{i} R_{i}
\end{gathered}
$$

Where $\varepsilon_{\mathrm{i}}, \sigma_{\mathrm{i}}$ and $\mathrm{R}_{\mathrm{i}}$ represent the contribution to the energy of dispersion, the diameter and the chain length of the functional group $i$ in a component which is composed of $\mathrm{n}_{\text {groups }}$ different groups, $\mathrm{n}_{\mathrm{i}}$ is the number of groups of type $i$ in the molecule.

We also consider the pseudo-ionization energy $J$ proposed by Nguyen Huynh et al.[15], as an additional group parameter. The molecular pseudo ionization energies $J$ can be calculated by a group contribution method:

$$
J=\sqrt{\left.\prod_{i=1}^{\sum_{i=1}^{\text {ngroups }}} n_{i}\right)} J_{i}^{n_{i}}
$$

\section{b. Polar parameters}


These parameters are involved in the polar term. The polar groups require two additional parameters: the dipole moment $\mu$ (or the quadrupole moment $\mathrm{Q}$ ) and the dipolar fraction $\mathrm{x}_{\mathrm{p}}^{\mu}$ ( or quadrupolar fraction $\mathrm{x}_{\mathrm{p}}^{\mathrm{Q}}$ ). In fact, polar fractions $\mathrm{x}_{\mathrm{p}}^{\mu}$ and $\mathrm{x}_{\mathrm{p}}^{\mathrm{Q}}$ are inversely proportional to the

chain length. Hence, the actual parameter used is rather the product $\left(\mathrm{x}_{\mathrm{p}}^{\mu} m\right.$ or $\left.\mathrm{x}_{\mathrm{p}}^{\mathrm{Q}} m\right)$ which represent the number of dipoles or quadrupoles in the molecule.

\section{Predictive use of GC-PPC-SAFT on hydrogen + oxygenated mixtures}

In order to investigate the trends that may exist in the solubility behavior of hydrogen in various solvents, the use of Henry's constant appears to be a relevant descriptor, as already discussed in our previous paper[21], [22] In fact, Henry's law constant is widely used to describe the low solubility of light solutes (such as hydrogen) in a variety of solvents over a wide temperature range[31]-[33]. When Henry's constant of a solute increases with temperature, it corresponds to a decrease in the solubility. In our case, the solute is hydrogen and the solvents are the molecules listed in our previous paper about hydrogen solubility. The Henry law constant of a solute in a solvent, $H_{i}$ is defined by the expression:

$$
H_{i}=\lim _{x_{i} \rightarrow 0}\left(\frac{f_{i}^{L}}{x_{i}}\right)
$$

Where $\boldsymbol{f}_{\boldsymbol{i}}^{\boldsymbol{L}}$ is the fugacity of hydrogen (solute $i$ ) in the liquid phase, $x_{i}$ is its mole fraction in the liquid phase.

The database used in this work has been analyzed in detail for its global coherence[34]. Beside the vapor-liquid equilibrium data, we also have in our database the solubility coefficients such as Ostwald coefficient, Bunsen coefficient and Kuenen coefficient. They have been converted into Henry's constant using the definitions in the IUPAC ${ }^{36}$ guide.

\section{Predictive approach:}


The original GC-PPC-SAFT model was first tested in pure prediction for the phase equilibrium calculation of $\mathrm{H}_{2}$-oxygenated compounds considered in the database. The GC-PPCSAFT parameters of hydrogen and oxygenated compounds were determined in previous studies[2][4][31], [32], [36], [37] and reused here (Table A.1). The $\mathrm{k}_{\mathrm{ij}}$ was predicted using Equation (10).As the pseudo-ionization parameters of some groups are not defined (aldehydes, ketones, esters,...), the $\mathrm{k}_{\mathrm{ij}}$ between hydrogen and molecules from these families are set equal to zero.

In terms of Henry's constants, a typical result is shown in Figure 1. We can see that GCSAFT significantly overestimates the experimental Henry constant (meaning it underestimates the solubility).

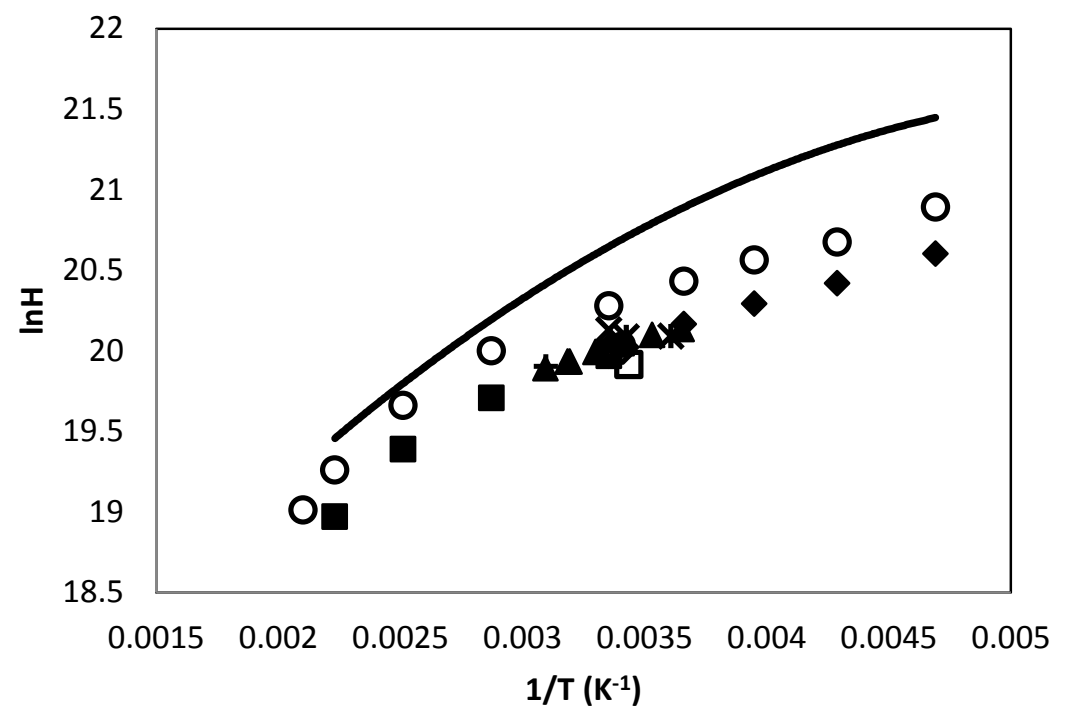

Figure 1: Diagram of $\operatorname{lnH}$ as a function of $1 / \mathrm{T}$ for the binary mixture hydrogen/ethanol. Experimental data are taken from Wainwright et al.[38] (๓), Brunner et al.[39] (), Makranczy et

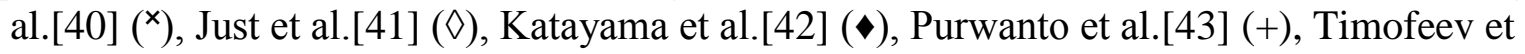
al.[44] (*), Maxted et al.[45] ( $\mathbf{\Delta})$, Luhring et al.[46] (•), pseudo-data by molecular simulation (o), predictive calculation by GC-PPC-SAFT with predictive $\mathrm{k}_{\mathrm{ij}}(-)$

\section{Correlative approach}

The usual way of improving the results consists in adjusting the binary parameter $\left(\mathrm{k}_{\mathrm{ij}}\right)$. When this is done, the results are dramatically improved (cf. Figure 2), many systems requiring a non-zero value $\mathrm{k}_{\mathrm{ij} \cdot}$ [47]-[49] 


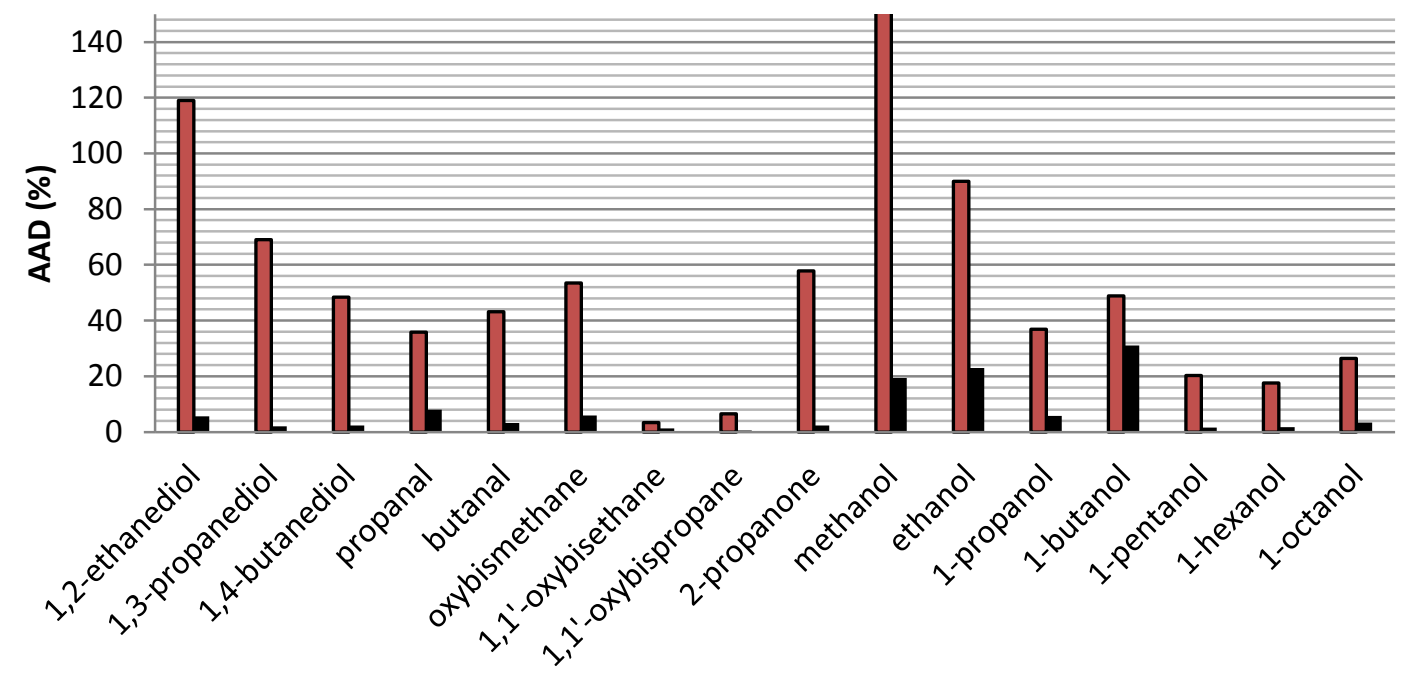

Figure 2: Deviations of Henry's constants of the binary mixtures $\mathrm{H}_{2}$-oxygenated components: without $\mathrm{k}_{\mathrm{ij}}$ regression $(\square)$, with $\mathrm{k}_{\mathrm{ij}}$ regression ( $\left.\mathbf{\square}\right)$

However, the adjusted $\mathrm{k}_{\mathrm{ij}}$ are mostly negative as depicted on Figure 3 . The numerical values are shown in Table B.1. Yet, in our approach decoupling polar interactions from the other ones, it has been arguedthat only positive $\mathrm{k}_{\mathrm{ij}}$ values can be justified from a theoretical point of view (see NguyenHuynh et al.[15]). In other words, the original Lohrentz - Berthelot combining rule on dispersive energy $\varepsilon_{i j}=\sqrt{\varepsilon_{i} \varepsilon_{j}}$ should overestimate the true dispersive interactions according to Hudson and McCoubrey.[27] Here, the opposite is observed: the 'net attraction' between the oxygenated species and hydrogen seems to be underestimated by the LohrenzBerthelot rule. Generally, this means that the polarity or cross association has been neglected (see figure 14)[50] or under estimated. Yet, to the best of our knowledgeafter a careful search of the open scientific literature, there is no evidence of such phenomenon with hydrogen.

One may wonder then if the hydrogen GC-PPC-SAFT parameterization should not be reconsidered. Several such parameters have been investigated using hydrogen + n-alkane VLE, and the best parameters are found to be those of Le Thi et al.[12] that are used here. It is not possible to determine hydrogen parameters using its vapor pressure and liquid molar volume, as is usually done for other components, because of its highly supercritical behavior, and because of its quantum behavior. This is why this set of parameters had to be determined on binary VLE. 
The same overestimation of Henry's constants is also observed with the Monte Carlo simulations (see Figure 1), yet to a smaller extent. These results suggest searching for other causes for the observed deviation between SAFT and experimental data.

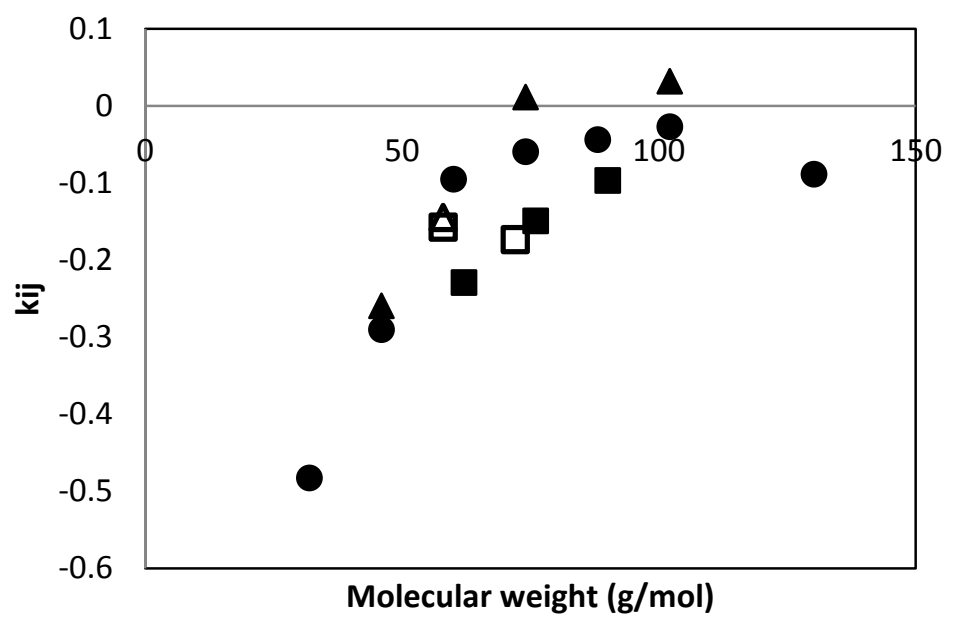

Figure 3: Values of $\mathrm{k}_{\mathrm{ij}}$ parameter as a function of molecular weight of chemical families: $\mathrm{H}_{2} /$ diol

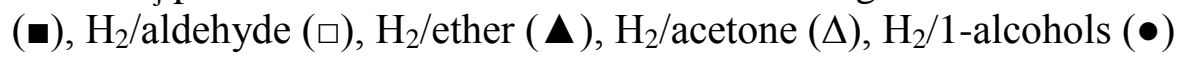

$\underline{\text { Search for an alternative approach }}$

An alternative explanation for the observed $\mathrm{k}_{\mathrm{ij}}$ is to assume that this behavior is not the result of a missing attractive contribution but to a decrease of the repulsion between hydrogen and oxygenated molecule.

Our analysis of this phenomenon starts with the work of Clever and al.[51] who studied the solubility of noble gases such as neon, krypton and helium in hydrocarbon solvents. A linear behavior of the gas solubility as a function of the free volume was observed. Recall that this volume is computed according to $V_{\text {free }}=V_{m}-V_{V d W}$ i.e. the difference between the molar volume (macroscopic observed volume) and the volume of van der Waals at 298.15K. Their study suggests that the gas fits into the spaces left by the solvent. The solubility seemed primarily governed by the probability of insertion of the gas molecule in the solvent. This behavior reflects the absence of high energy interaction (polar or association) between rare gases and solvent.

We made a similar plot regarding solubility of hydrogen in a large variety of solvents as follows. Remind that the relationship between concentration and Henry's constant is: 


$$
C=\frac{V_{m} P}{H} \approx \frac{\text { const }}{H}
$$

Where $\mathrm{V}_{\mathrm{m}}$ is the molar volume of solvent, $\mathrm{P}$ is the total pressure and $\mathrm{C}$ is the gas concentration in the liquid phase $(\mathrm{mol} / \mathrm{L})$.

Figure 4 shows the gas concentration (in mol/L) which is essentially the inverse of Henry's constant, as a function of the ratio of the free volume and molar liquid volume. In this work, the values of the molar volume and the Van der Waals volume at $298.15 \mathrm{~K}$ are taken from the DIPPR database[52].

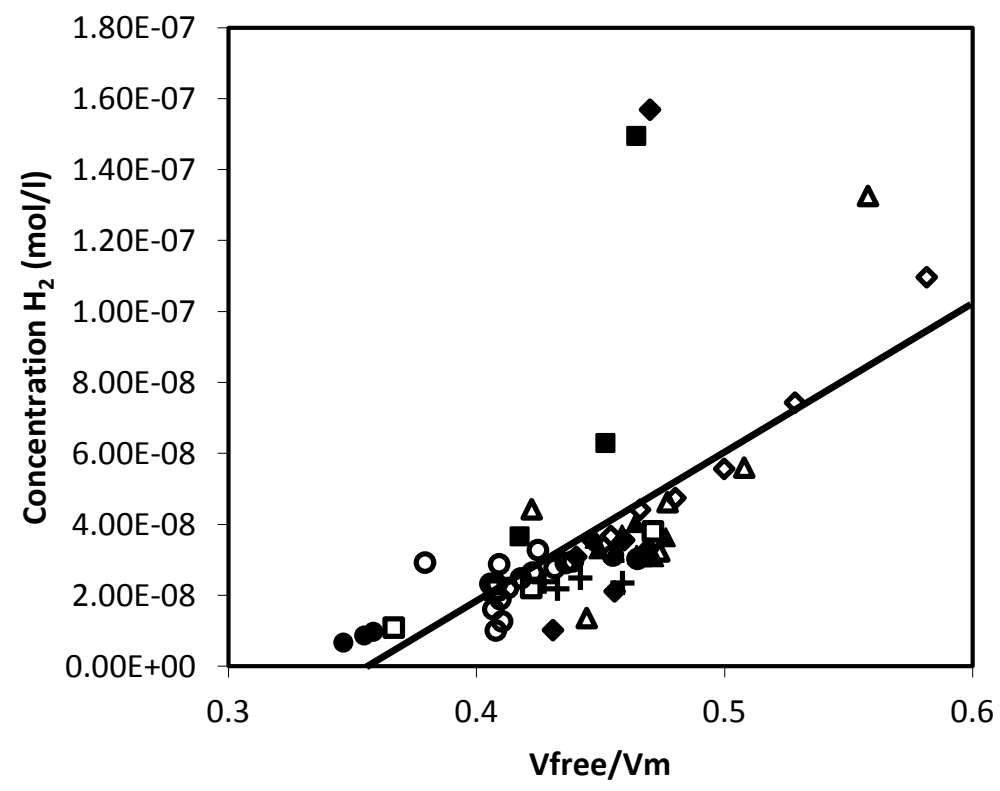

Figure 4: Hydrogen concentration in oxygen-bearing solvents as a function of the ratio of free volume ( $\boldsymbol{V}_{\text {free }}=\boldsymbol{V}_{\boldsymbol{m}}-\boldsymbol{V}_{\boldsymbol{V} \boldsymbol{d} \boldsymbol{W}}$, where $\mathrm{VVdW}$ is the Van der Waals volume) and molar volume $\left(\mathrm{V}_{\mathrm{m}}\right)$ at $298.15 \mathrm{~K}$ : alcohols $(\mathrm{o})$, alkanes $(\diamond)$, esters $(\boldsymbol{\Delta})$, ethers $(\Delta)$, ketones $(\square)$, diols $(\bullet)$, aldehydes $(\mathbf{\square})$, aromatics $(+)$, heterocylics $(\diamond)$

It is noted that in Figure 4, the hydrogen solubility in the solvent increases with the free volume. Despite the data dispersion, the hydrogen solubility seems strongly (mainly) dependent at a first good approximation on the free volume fraction and not on the chemical nature of the solvent (within experimental dispersion). The free volume is conditioned by the repulsive 
interactions. In order to model the solubility of hydrogen in oxygenated environments, it is necessary to carefully consider these interactions and in particular combining rules on diameters.

Notice first that the additive combining rule (see Equation 11) is strictly observed in the case of hard spheres (or segments) but not necessarily when the segments interact via a soft potential. Several authors[53], [54] argued that a geometric mixing rule would be better justified from a theoretical point of view. This means that one should use a modified combining rule:

$$
\sigma_{i j}=\frac{\sigma_{i}+\sigma_{j}}{2}\left(1-l_{i j}\right)
$$

With non-zero $\mathrm{l}_{\mathrm{ij}}$ values.

Spackman[55] has testedadditivity of cross van der Waals atomic diameters and observedthat non additivity is higher when hydrogen atoms (if compared to other atoms) are involved.

The observation of Spackman[55] maybe understood if one acknowledges that repulsion is driven by electron clouds overlap. In the case of $\mathrm{H}$ atom, since it has no kernel electrons, its electron cloud is highly deformable. In the case of $\mathrm{H}_{2}$ molecule, it was even shown by Williams[56] that the repulsion centers in hydrogen was to be shifted from nuclei to bond center in order to fit well the repulsion energy between two hydrogen molecules. This foreshortening effect was supported by X-Ray and neutron diffraction.

Those phenomena are of importance since, as discussed by Williams and Craycroft[56], the periphery of most organic compounds is composed of hydrogen. This may be a cause for breaking the additive combining rule on diameter. The repulsion operated by $\mathrm{H}$ atom may depend:

- On the attached atom $(\mathrm{C}, \mathrm{O}, \ldots)$ to $\mathrm{H}$. The effect may be important if highly electronegative atoms are bonded to hydrogen. In particular, $\mathrm{H}$ acquires an electron deficit along the series $\mathrm{H}(\mathrm{C}), \mathrm{H}(\mathrm{N})$ and $\mathrm{H}(\mathrm{O})$. This deficit increases the deformation of the cloud and reduces the repulsion in the same sequence.

- On the chemical environment via electrical field generated by polar molecules that can distort electron clouds (polarizability effect) especially when they are close.

The hydrogen molecule itself can be regarded as very specific. It is a small molecule that can fill the cavities in the liquid solvent more easily than the bigger chain molecules. In other 
words, it is expected that hydrogen can easily go very close to solvent molecules. As a consequence, in the solubility conditions, hydrogen is probably very sensitive to repulsive interactions, more than bigger chain molecules. All those elements put in the light the complexity of repulsive interactions in hydrogen containing systems.

From this discussion, it is suggested that hydrogen+solvent systems modeling may be driven by repulsion and that the use of non-additivediameters may help improving the predictive power for the solubility of hydrogen in various solvents and especially oxygenated solvents due to their high polarity.

\section{Extension of GC-PPC-SAFT to non-additive square wells chains}

The equation of state derived from the above potential may be obtained by using perturbation techniques that start by subdividing the potential into a reference and a perturbation part.In standard procedures, one would choose the reference part as repulsive. This would lead to deal with non-additive hard chains as reference fluid for which little is known; in particular analytical expression of inter-segment distribution functions are unknown and simulation data for these functions are not available whereas they are needed to compute the perturbation part.

So, rather than starting from the very beginning with the development of a new equation of state, we decided to base our work on the proposal of Malakhov and Volkov[22], who developed a model of non-additive chains of hard spheres using a specifically designed perturbation.

In a previous paper[21], we proposed an equation of state of non-additive square-well chains developed on the bases of the work of Malakhov and Volkov[22].

The segment $i$-segment jinteraction potential $\mathrm{u}_{\mathrm{ij}}$ is written as:

$$
u_{i j}(r)=\left\{\begin{array}{lr}
\infty & r<\sigma_{i j} \\
-\varepsilon_{i j} \sigma_{i j} \leq r<\lambda \sigma_{i j} \\
0 & r \geq \lambda \sigma_{i j}
\end{array}\right.
$$


where $\mathrm{r}$ is the distance between two segments, $\sigma_{\mathrm{ij}}$ is the cross diameter and $\sigma_{i j}=\frac{\sigma_{i}+\sigma_{j}}{2}\left(1-l_{i j}\right)$, $\varepsilon_{i j}$ denotes the depth of the potential well, and $\lambda$ is the reduced well-width. Throughout this work a well-width of 1.5 is assumed.

Using a perturbation, the final equation of state consists of two terms, the additive squarewell chain EoS (reference) and a correction accounting for the non-additivity (NA):

$$
\frac{A}{N k T}=\frac{A^{S W C}}{N k T}+\frac{A^{N A}}{N k T}
$$

where $\mathrm{A}$ is the Helmholtz energy, $\mathrm{N}$ is the total number of molecules, $\mathrm{k}$ is the Boltzmann constant, and $\mathrm{T}$ is the absolute temperature. $A^{S W C}$ denotes the additive square well chain Helmholtz energy. The contribution $A^{N A}$ is evaluated here at first order and it contains the non additivity correction which is given by :

$$
\begin{aligned}
\frac{A^{N A}}{N k T}=-2 \pi \rho & \sum_{i} \sum_{j} x_{i} x_{j} m_{i} m_{j} \sigma_{i j}^{3} l_{i j}\left[g_{i j}\left(\sigma_{i j}^{+}\right)-\lambda^{3} g_{i j}\left(\lambda \sigma_{i j}^{-}\right)\right. \\
& \left.+e^{-\beta \varepsilon_{i j} \lambda^{3} g_{i j}}\left(\lambda \sigma_{i j}^{-}\right)\right]
\end{aligned}
$$

In this expression, we can see the presence of non-additive parameter $l_{\mathrm{ij}}$ in the new contribution of GC-PPC-SAFT Equation of state. A non-zero $1_{\mathrm{ij}}$ allows adjusting the repulsive interaction between molecules. This expression requires having average inter - segment distribution functions at contact $g_{i j}\left(r=\sigma_{i j}^{+}\right)$and at limit $g_{i j}\left(r=\lambda . \sigma_{i j}^{-}\right)$for a chain of spheres interacting via an additive square well potential. Notice that these functions depend on the chain lengths $m_{i}$ and $m_{j}$. They have been mainly studied in the context of chains of hard spheres. The average inter-segment distribution function is obtained from:

$$
g_{i j}=\frac{4 g_{T_{i} T_{j}}+2\left(m_{i}-2\right) g_{I_{i} T_{j}}+2\left(m_{j}-2\right) g_{I_{j} T_{i}}+\left(m_{j}-2\right)\left(m_{i}-2\right) g_{I_{i} I_{j}}}{m_{i} m_{j}}
$$

Where 


$$
\begin{gathered}
g_{T_{i} T_{j}}=g_{D D}(28) \\
g_{I_{i} T_{j}}=g_{I_{j} T_{i}}=\frac{3}{2} g_{D D}-\frac{1}{2} g_{S S}(29) \\
g_{I_{i} I_{j}}=2 g_{D D}-g_{S S}(30)
\end{gathered}
$$

The dimer-dimer $\left(\mathrm{g}_{\mathrm{DD}}\right)$ and segment-segment $\left(\mathrm{g}_{\mathrm{SS}}\right)$ inter-segment distribution function can be fitted to following empirical expression according to B.J. Zhang et al.[57]:

$$
\begin{aligned}
& g_{S S}\left(\sigma^{+}, \eta, \frac{\varepsilon}{k T}\right)=\sum_{p=0}^{4} \sum_{q=1}^{4} a_{p q}\left(\frac{\varepsilon}{k T}\right)^{p} \frac{\eta^{q-1}}{(1-\eta)^{q}} \\
& g_{D D}\left(\sigma^{+}, \eta, \frac{\varepsilon}{k T}\right)=\sum_{p=0}^{4} \sum_{q=1}^{4} b_{p q}\left(\frac{\varepsilon}{k T}\right)^{p} \frac{\eta^{q-1}}{(1-\eta)^{q}}
\end{aligned}
$$

Where $\eta=\zeta_{3}$ and $a_{p q}, b_{p q}$ are universal coefficients that are determined by regression of distribution function data at contact $\left(r=\sigma_{i j}^{r e f}\right)$ obtained by Monte Carlo simulation[58], [59]over the temperature-density range $0 \leq \beta \varepsilon \leq 0.7$ ( $\mathrm{T}^{*}>1.42$ ) and $0 \leq \eta \leq 0.5$. Their values are listed in Table III-6 and Table III-7 in Appendix III-A. In this work, we shall use these functions, and evaluate them for mixtures at $\eta$ and $\beta \varepsilon_{i j}$.

Note that in equation (26), we also need the distribution functions evaluated at $r=$ $\lambda . \sigma_{i j}^{S W C}$. As mentioned above, in this development we use the value of $\lambda$ equal to 1.5 which is the most current width in square well potential where data are more abundant in the literature[60][62]. Because the relations in equations (31) and (32) have given good results for the determination of $g_{S, S}$ and $g_{D, D}$ at contact, we assumed that these relations also allow to well represent the inter-segment distribution functions of spheres and dimers at $r=\lambda . \sigma_{i j}^{S W C}$. 
Therefore, we repeat the work of B. J. Zhang et al.[57] work on determination of $g_{S, S}$ and $g_{D, D}$ at $r=\lambda \cdot \sigma_{i j}^{S W C}$.

Table 1: Summary of conditions of Monte Carlo simulation for fitting and for the validation

\begin{tabular}{|l|c|c|c|c|c|}
\hline & $\mathbf{m}$ & $\boldsymbol{T}$ & $\mathbf{T}^{*}$ & Method & Authors \\
\hline For fitting & 1 & $0.05 \leq \eta \leq 0.45$ & $1.5,2,3,10$ & NVT & Largo et al[63] \\
\cline { 2 - 6 } & 2 & $0 \leq \eta \leq 0.4$ & $1.5,2$ & BGY Equation & Lipson et al[61] \\
\hline For validation & 4 & $0 \leq \eta \leq 0.35$ & 1.5 & BGY Equation & Lipson et al[62] \\
\cline { 2 - 6 } & $6,8,16$ & $0 \leq \eta \leq 0.3$ & 1.5 & BGY Equation & Lipson et al[60] \\
\cline { 2 - 6 } & 4 & $0.05 \leq \eta \leq 0.45$ & 1.5 & NVT & Tavares et al[58] \\
\cline { 2 - 6 } & 8 & $0.36 \leq \eta \leq 0.45$ & 1.5 & NVT & Tavares et al[58] \\
\cline { 2 - 6 } & 16 & $0.36 \leq \eta \leq 0.45$ & 1.5 & NVT & Tavares et al[58] \\
\cline { 2 - 6 } & 4 & $0 \leq \eta \leq 0.5$ & 1.5 & NPT & This work \\
\hline
\end{tabular}

The values of $\mathrm{a}_{\mathrm{pq}}$ and $\mathrm{b}_{\mathrm{pq}}$ at $r=\lambda . \sigma_{i j}^{S W C}$ are obtained by regressing the data from the study of Lipson et al.[61], [62]for $g_{S W D}\left(\lambda \sigma^{+}, \eta, \beta \varepsilon\right)(\mathrm{m}=2)$ and from the study of Largo et al.[63] for $g_{S W S}\left(\lambda \sigma^{+}, \eta, \beta \varepsilon\right)(\mathrm{m}=1)$ with the conditions detailed in Table 1 . In fact, there are different methods to obtain the inter-segment distribution function. In Table 1, we can see three typical methods. The first method is the NVT that consists a Monte Carlo simulation where we impose the temperature, the volume and the number of particles of the system. The second method named 'NPT' is similar to the NVT method except that pressure is imposed instead of volume. The third method is called BYG integral equation. This method has been solved for many shortranged potentials such as hard sphere[64], [65], square well[66] and Lennard-Jones[67], [68] fluids. See the original articles for more details.

The values of these coefficients are listed in Tables D.1 to D.4.

Let us recall that the potential in PC-SAFT is not exactly square well but has a shoulder to take into account the 'soft' character of the repulsive interactions (see Figure 5) 


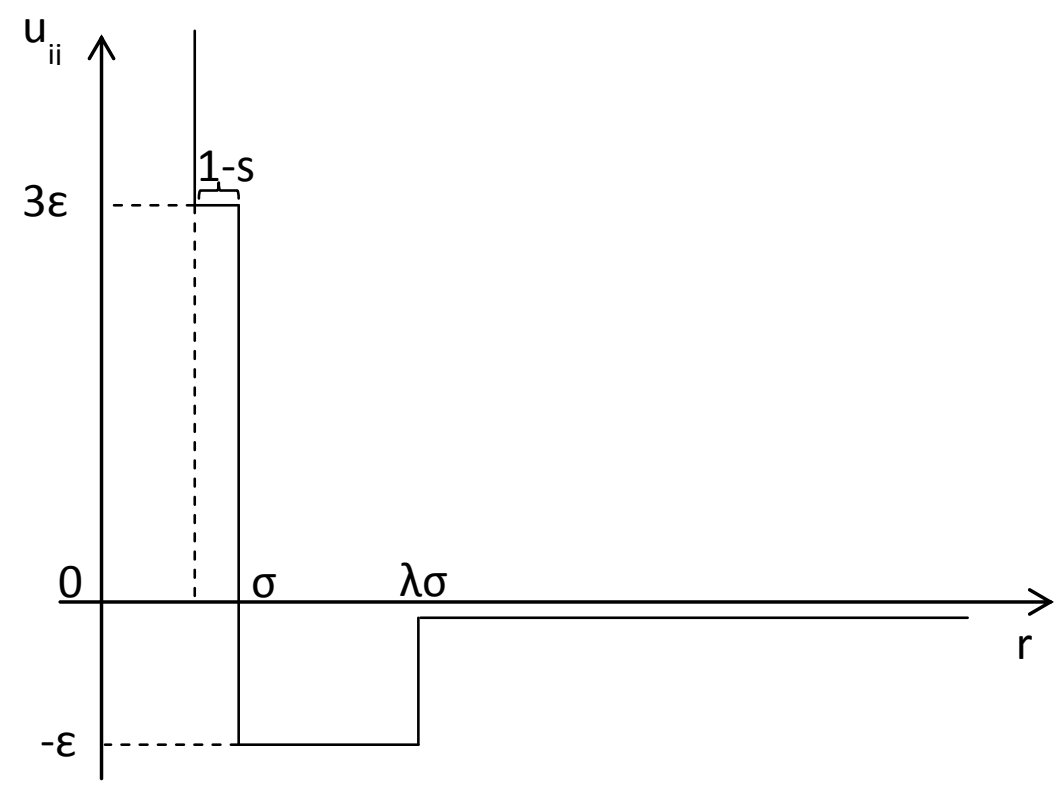

Figure 5: Potential modified in PC-SAFT Equation of state

$\boldsymbol{u}(\boldsymbol{r})=\left\{\begin{array}{lr}\infty & \boldsymbol{r}<(1-s) \sigma_{i j} \\ 3 \varepsilon & (1-s) \sigma_{i j}<r<\sigma_{i j}\end{array}\right.$

in addition to the 'square well' part

$\boldsymbol{u}(\boldsymbol{r})=\left\{\begin{array}{rc}-\boldsymbol{\varepsilon} & \boldsymbol{\sigma}_{i j}<r<\lambda \sigma_{i j} \\ \mathbf{0} & \boldsymbol{r}>\lambda \sigma_{i j}\end{array}\right.$

Strictly speaking, Equation (26) applies only for the square well chains (s = 0). For PCSAFT, we could adopt the same methodology as in the previous paper to the soft potential of PCSAFT to obtain the analogous expression (26) applicable to the full PC-SAFT equation of state. The latter would be more complex involving two more distribution functions $g_{i j}\left(r=\sigma_{i j}^{-}\right)$and 
$g_{i j}\left(r=(1-s) \cdot \sigma_{i j}^{+}\right)$. But to the best our knowledge, the analytical expressions of these functions are unknown, and their values have not been estimated by simulation. However, these functions correspond to distances where the potential is 'repulsive'; we can therefore expect that their values are smaller than those of $g_{i j}\left(r=\sigma_{i j}^{+}\right)$and $g_{i j}\left(r=\lambda \cdot \sigma_{i j}^{-}\right)$involved in the Equation (26). For this reason, and in order to maintain our model as simple as possible, we have chosen to neglect the non-additive terms with $g_{i j}\left(r=\sigma_{i j}^{-}\right)$and $g_{i j}\left(r=(1-s) . \sigma_{i j}^{-}\right)$. This is equivalent to using the expression (26) to correct the PC-SAFT non-additive interactions (i.e. $A^{S W C}=$ $\left.A^{P C-S A F T}\right)$. But in this case, the potential is a full potential with shoulder. In the same spirit as the pertubative treatment of the 'soft' potential which leads in particular to introduce a hard sphere diameter $\mathrm{d}(\mathrm{T})$ that depends on temperature as in Equation (4), we make the following approximations for the distribution functions: $g_{i j}\left(r=\sigma_{i j}^{+}\right) \approx g_{i j}^{S W}\left(r=d_{i j}^{+}\right)$and $g_{i j}\left(r=\sigma_{i j}^{+}\right) \approx$ $g_{i j}^{S W}\left(r=d_{i j}^{+}\right)$.

$\mathrm{SW}$ refers to the square well potential and $\mathrm{d}_{\mathrm{ij}}$ is the additive cross hard sphere diameter

$\left(d_{i j}=\frac{d_{i i}+d_{j j}}{2}\right)$. This means that, from the perspective of calculating distribution functions, the full potential is equivalent to a square well potential but parameterized by $\mathrm{d}_{\mathrm{ij}}$.

The final equations used and their derivatives are available in Appendix C.

\section{Results of the prediction and correlation of hydrogen solubility in oxygenated solvents}

The use of a predictive scheme for computing thermodynamic properties of systems containing gases and oxygenated compounds requires the simultaneous use of $\mathrm{k}_{\mathrm{ij}}$ and $\mathrm{l}_{\mathrm{ij}}$ parameters. The determination of the required parameters is done in two steps. First, the pseudoionization parameters of the oxygenated groups are determined, and second, the $\mathrm{l}_{\mathrm{ij}}$ parameters are regressed.

\subsection{Determination the pseudo-ionization energy of oxygenated groups}

The values of pseudo-ionization energy of hydroxyl group and ester group have already been determined by NguyenHuynh et al[23], [69]. For the correlation of $\mathrm{k}_{\mathrm{ij}}$ of systems containing 
the other oxygenated groups such as ether, aldehyde or ketone, it is necessary to determine the pseudo-ionization energy of these groups. Considering the lack of data, we will consider that all oxygenated groups other than esters and alcohols have the same value of pseudo ionization energy.

To obtain these pseudo-ionization energy we need to model small gas + oxygenated compounds as in previous studies. In those earlier studies the small gas was $\mathrm{CO}_{2}$. Here only a few Henry constant data are available for $\mathrm{CO}_{2}$ in oxygenated compounds systems as they are expected to need no $l_{\mathrm{ij}}$. In order to verify this, a regression of parameter $1_{\mathrm{ij}}$ by GC-PPC-SAFT with a predictive $\mathrm{k}_{\mathrm{ij}}$ was performed on the Henry constant of this gas with alcohols (for which a predictive $\mathrm{k}_{\mathrm{ij}}$ can be computed, using the $J_{O H}$ from previous work as shown in the parameter table of Appendix A). In Figure 6, we observe that the numerical values $1_{i j}$ of ethane/alcohols systems are approximately zero except in the case of methanol/ethane. This validates the assumption that the impact of non-additivity effect is negligible in the case of a hydrocarbon gas in oxygenated solvents.

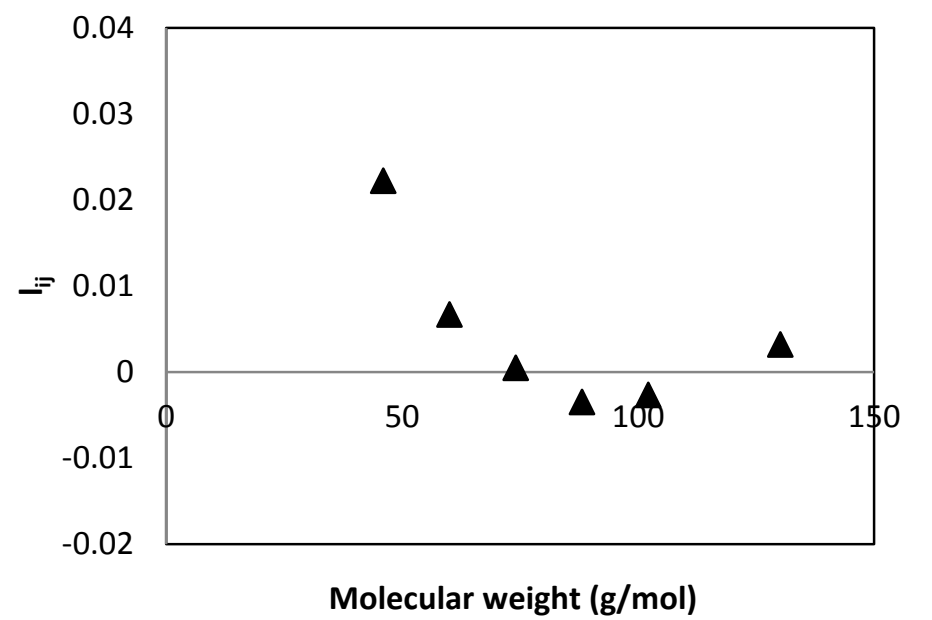

Figure 6: Regressed values of non-additive parameter $l_{i j}$ for binary mixtures of ethane/alcohols $(\mathbf{\Delta})$

In order to determine the pseudo-ionization energy of oxygenated groups, we followed a two-step procedure. First, $\mathrm{k}_{\mathrm{ij}}$ values were adjusted by regressing the Henry constants of ethane in oxygenated component with the objective function : 


$$
F_{o b j}=\frac{1}{N} \sum\left(\frac{H^{c a l}-H^{e x p}}{H^{e x p}}\right)^{2}
$$

For this work, we have collected all available Henry constants in the database. It contains followingbinary systems: $\mathrm{C}_{2} \mathrm{H}_{6} /$ propanal[41], $\mathrm{C}_{2} \mathrm{H}_{6} /$ diethyl ether[42], $\mathrm{C}_{2} \mathrm{H}_{6} / 1$,2-ethanediol[43][46], $\mathrm{C}_{2} \mathrm{H}_{6} /$ acetone[42][9], [16], [49], $\mathrm{C}_{2} \mathrm{H}_{6} /$ methyl acetate[42][49], $\mathrm{C}_{2} \mathrm{H}_{6} /$ ethyl acetate[51], [70], $\mathrm{C}_{2} \mathrm{H}_{6} /$ pentyl acetate[70]. All available data are provided in of Table B.1 and Table B.6.

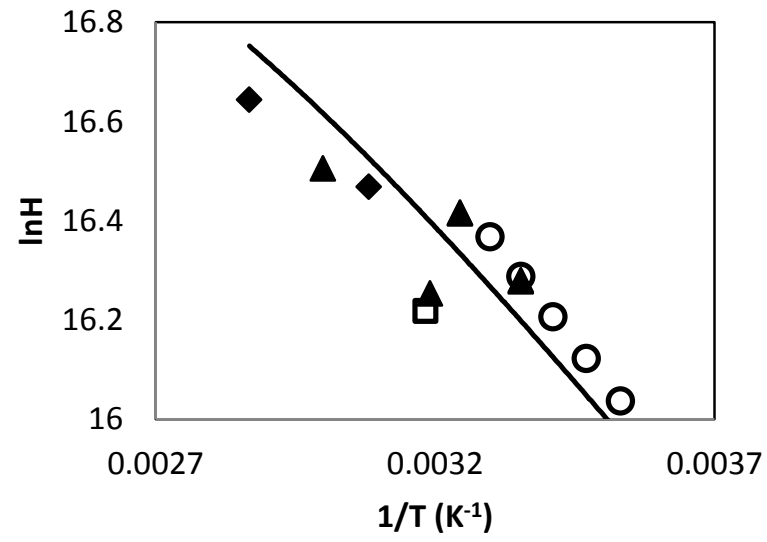

Figure 7 : Diagram of $\ln \mathrm{H}$ as a function of $1 / \mathrm{T}$ for the binary mixture ethane/1-propanol. Experimental data are taken from Gjaldbaek et al.[71] ( $\mathbf{\Delta})$,Yaacobi et al.[72] (o),Suzuki et al.[73] $(\Delta)$, Kodama et al.[74] (ם), JimenezGallegis et al.[75] ( $\bullet$, GC-PPC-SAFT (一)

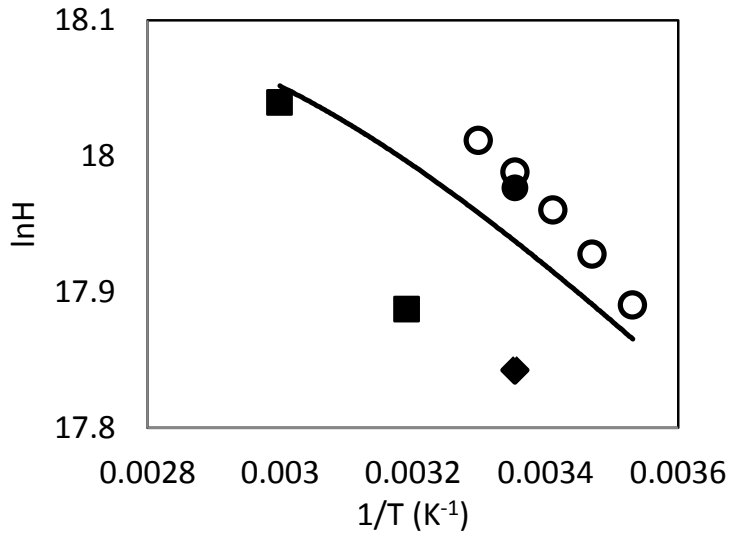

Figure 8: Diagram of $\ln \mathrm{H}$ as a function of $1 / \mathrm{T}$ for the binary mixture methane/1-propanol. Experimental data are taken from Makranczy et al.[40] (४), Bo. S et al.[76] (•), Yaacobi et al.[72] (o), Suzuki et al.[73] (口), GC-PPCSAFT (一)

In a second step, the values of $J$ for the oxygenated groups are determined by fitting the regressed values of $\mathrm{k}_{\mathrm{ij}}$ parameter for binary mixtures of ethane/oxygenated compound according to Equations (10) and (18).

Table 2: Pseudo-ionization Energies and Experimental Values of oxygenated solvents

\begin{tabular}{|l|c|c|}
\hline Component & Pseudo-ionization energy (eV) & Experimental ionization energy[77](eV) \\
\hline Acetone & 14.98 & $9.703 \pm 0.006$ \\
\hline Diethyl ether & 10.56 & $9.51 \pm 0.03$ \\
\hline
\end{tabular}




\begin{tabular}{|l|l|r|}
\hline Propanal & 9.74 & $9.96 \pm 0.01$ \\
\hline
\end{tabular}

The value $J$ of the oxygenated groups was acceptable because it appears that the values of pseudo-ionization energy of oxygen-bearing solvent calculated by the group contribution are close to the experimental ionization energy (see Table 2). The values of pseudo-ionization energy $J$ of different oxygenated groups are given in Table 3.

Table 3: Values of pseudo-ionization energy of different oxygenated groups

\begin{tabular}{|l|c|}
\hline Group & Pseudo-ionization energy (eV) \\
\hline alkanol & 28.008 \\
\hline ester & 14 \\
\hline Other oxygenated groups & 6.5 \\
\hline
\end{tabular}

\subsection{Predictive method of non-additive parameter $\mathbf{l}_{\mathrm{ij}}$}

In the proposed approach, $\mathrm{k}_{\mathrm{ij}}$ is computed using the equation (10), while it is suggested to determine $\mathrm{l}_{\mathrm{ij}}$ using a group contribution approach as proposed by Le Thi et al[12]which is the arithmetic average weighted by the number of segment - segment interactions between their molecules :

$$
l_{i j}=\frac{1}{n_{i}^{\text {group }} n_{j}^{\text {group }}} \sum_{k} \sum_{l} n_{i}^{\text {group } k} n_{j}^{\text {group } l} l^{k l}
$$

Where $n_{i}^{\text {group } k}, n_{j}^{\text {group }} l$ is the number of groups k in molecule $i$ and groups $l$ in molecule $j ; l^{k l}$ is the non-additive parameter between groupskandl.

From earlier studies[12], it appears that the impact of the non-additivity of the square wells on hydrogen/n-alkane systems is negligible (this means that $l^{k l} \mathrm{H}_{2} / \mathrm{CH}_{2}$ and $l^{k l} \mathrm{H}_{2} / \mathrm{CH}_{3}$ are zero), thus in the equation (34), we only need to determine the value of $l^{k l}$ between $\mathrm{H}_{2}$ and an oxygenated group. Using the available data of Henry constants of hydrogen in different solvents 
(which are published in Trinh et al.[34]) in predictive GC-PPC-SAFTmodel, $l^{k l}$ for $\mathrm{H}_{2}$ /oxygenated groups is regressed and shown in Table 2.

Figure 9 compares the resulting computed $1_{i j}$ from Equation (34) with molecular $\left(\mathrm{H}_{2}+\right.$ solvent $)$ values that have been regressed separately. It means that the points in Figure 9 are the molecule - molecule values of $1_{\mathrm{ij}}$ regressed on experimental data of mixtures containing hydrogen and the different alcohols. The black line in this figure represents the molecule molecule values of $1_{\mathrm{ij}}$ calculated by Equation (34) in which the $l^{k l}$ group-group are regressed on the experimental data in the database. We can see that the longer the chains the lower thevalue of $\mathrm{l}_{\mathrm{ij}}$ parameter. The Equation (34) fits this behavior.

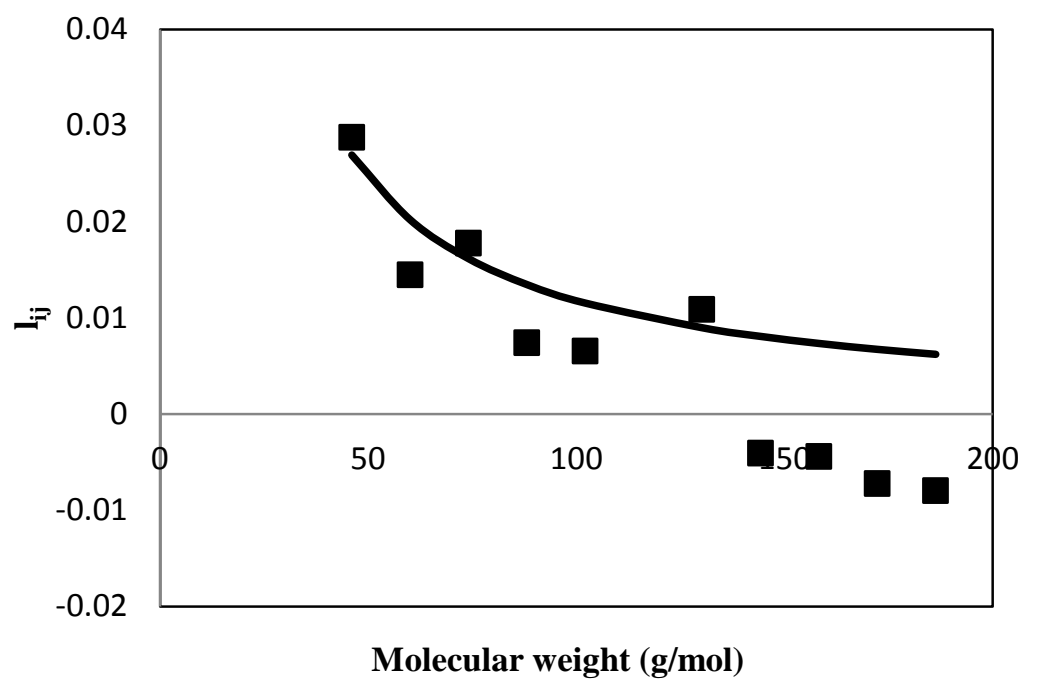

Figure 9: Regressed and correlated values of non-additive parameter $1_{\mathrm{ij}}$ for binary mixture: $\mathrm{H}_{2} /$ alcohol (a), $\mathrm{l}_{\mathrm{ij}}$ correlated curve for $\mathrm{H}_{2} /$ alcohol (-)

The value of $l^{k l}$ for $\mathrm{H}_{2}$ /-O- was found to be very small (-0.007). Figure 10 shows that the impact of this value is not significant on the prediction of Henry's constant of hydrogen in diethyl ether. It means that the influence of non-additive effect is not considerable. Therefore, in this work we consider that $l^{k l} \mathrm{H}_{2} /$-O- is equal to zero. We can observe in Table 4, that the more polar and associative the solvent the higher the value of the non-additive parameter $l^{k l}$. For example, the polarity of $\mathrm{OH}$ and $\mathrm{CHO}$ group are high, therefore, the $l^{k l}$ values between these groups and hydrogen are higher than those with the other oxygenated groups. This is in 
accordance with the discussion in section 3 of this article where it was stated that the polar molecules create an electric field that can distort the electron cloud of hydrogen molecule.

Table 4: Correlated values of $\boldsymbol{l}^{k l} \mathrm{H}_{2} /$ oxygenated group by using equation (34)

\begin{tabular}{|c|c|c|c|c|c|c|c|}
\hline & $\mathbf{H}_{2} / \mathbf{O H}$ & $\mathbf{H}_{2} / \mathbf{C H O}$ & $\mathbf{H}_{2} / \mathbf{C O O}$ & $\mathbf{H}_{2} / \mathbf{H C O O}$ & $\mathbf{H}_{2} /-\mathbf{O}-$ & $\mathbf{H}_{2} / \mathbf{C H}_{\mathbf{2}}$ & $\mathbf{H}_{2} / \mathbf{C H}_{\mathbf{3}}$ \\
\hline $\mathrm{l}_{\mathrm{ij}}$ & 0.081 & 0.099 & 0.053 & 0.046 & 0 & 0 & 0 \\
\hline
\end{tabular}

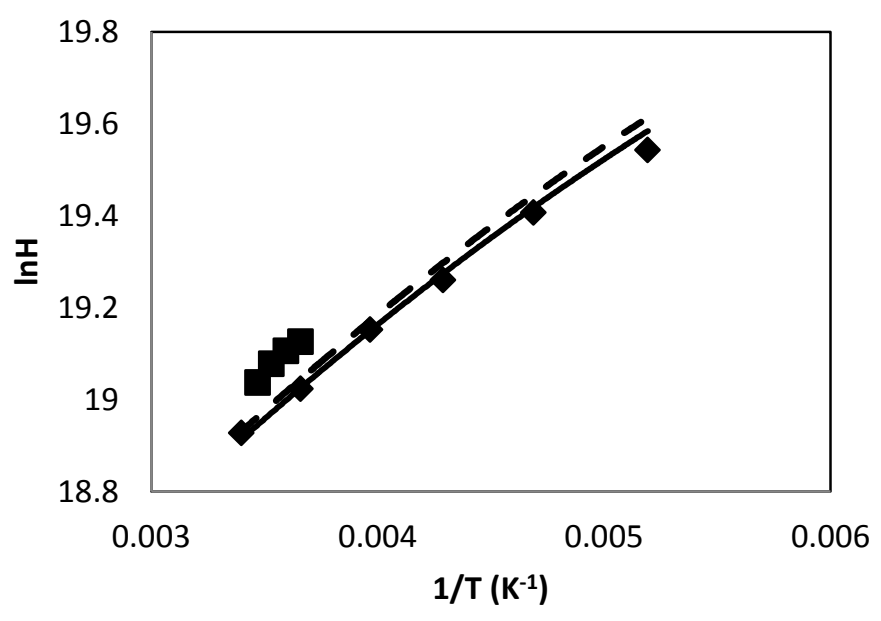

Figure 10: Diagram of $\mathrm{lnH}$ as a function of $1 / \mathrm{T}$ for the binary mixture hydrogen/diethyl ether. Experimental data are taken from Krichevskii et al.[78] (४); Michels et al.[79] (घ); predictive calculation by GC-PPC-SAFT with predictive $\mathrm{k}_{\mathrm{ij}}$ and $\mathrm{l}_{\mathrm{ij}}(\boldsymbol{C})$; GC-PPC-SAFT (only $\mathrm{k}_{\mathrm{ij}}$ ) $(--)$

With this predictive method for non-additive parameter $\mathrm{l}_{\mathrm{ij}}$, we can obtain satisfactory results in calculation of Henry's constant at high temperatures. As observed in the four systems of hydrogen with 1-propanol, ethanol, methyl acetate and propanal in the figures below, we see that at low and average temperature, GC-PPC-SAFT allow predicting the Henry constant with acceptable deviations. At high temperature, a good agreement between the calculation of GCPPC-SAFT and the results obtained by molecular simulation[21]is found.

We also compared the predictions using GC-PPC-SAFT with those by PSRK[11], an equation of state that is often used in engineering. We observe that PSRK predictions may sometimes be accurate, but sometimes over- or underestimate the data significantly. For 
example, we note that either PSRK cannot reproduce well the shape of Henry's constant (cf. Figure 13) or completely overestimates the Henry constants (cf. Figure 14). 

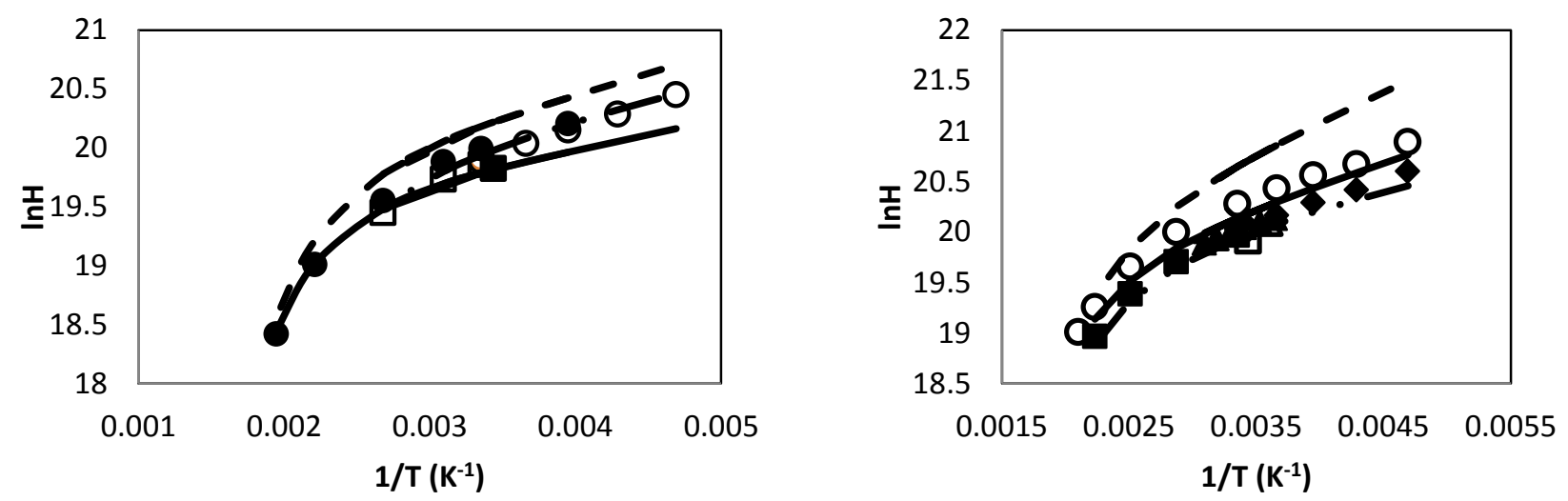

Figure 11: Diagram of $\ln \mathrm{H}$ as a function of $1 / \mathrm{T}$ for Figure 12: Diagram of $\ln \mathrm{H}$ as a function of $1 / \mathrm{T}$ the binary mixture hydrogen/1-propanol. for the binary mixture hydrogen/ethanol. Experimental data are taken from Makranczy et Experimental data are taken from Wainwright et al.[40] (०), Katayama et al.[42] (०), Wainwright et al.[38] (๘), Brunner et al.[39] (口), Makranczy et al.[38] (๘), Brunner et al.[80] (口); pseudo-data by al.[40] ( $\left.{ }^{\times}\right)$, Just et al.[41] ( $\left.\diamond\right)$, Katayama et al.[42] molecular simulation $(\bullet)$; predictive calculation by ( $\bullet$, Purwanto et al.[43] (+), Timofeev et al.[44] GC-PPC-SAFT with predictive $\mathrm{k}_{\mathrm{ij}}$ and $\mathrm{l}_{\mathrm{ij}}(\boldsymbol{-})$; GC- $(\Delta)$, Maxted et al.[45] ( $\left.\mathbf{\Delta}\right)$, Luhring et al.[46] PPC-SAFT (only $\mathrm{k}_{\mathrm{ij}}$ ) (- - ); calculation by PSRK (•),pseudo-data by molecular simulation (o), (一"-二)

predictive calculation by GC-PPC-SAFT with predictive $\mathrm{k}_{\mathrm{ij}}$ and $\mathrm{l}_{\mathrm{ij}}\left(\right.$ (一);GC-PPC-SAFT (only $\mathrm{k}_{\mathrm{ij}}$ ) (- - -) ; calculation by PSRK (---_)
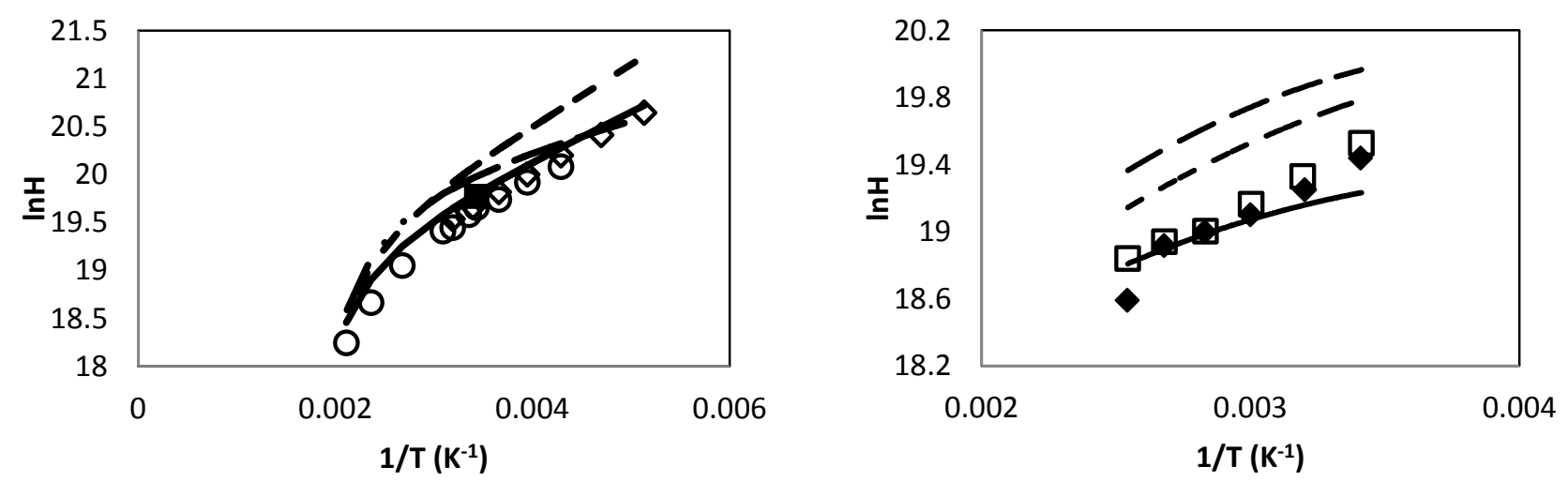

Figure 13: Diagram of $\ln H$ as a function of $1 / \mathrm{T}$ for Figure 14: Diagram of $\ln H$ as a function of $1 / \mathrm{T}$ the binary mixture hydrogen/methyl acetate. for the binary mixture hydrogen/propanal. Experimental data are taken from Horiuti et al.[81] Experimental data are taken from Vasileva et $(\diamond)$, Wainwright et al.[38] (ロ); pseudo-data by al.[82] ( $\square, \bullet)$; predictive calculation by GC-PPCmolecular simulation (o); predictive calculation by SAFT ( $\mathrm{k}_{\mathrm{ij}}$ and $\left.\mathrm{l}_{\mathrm{ij}}\right)(-)$; GC-PPC-SAFT (only $\mathrm{k}_{\mathrm{ij}}$ ) GC-PPC-SAFT $\left(\mathrm{k}_{\mathrm{ij}}\right.$ and $\left.\mathrm{l}_{\mathrm{ij}}\right)(-)$; GC-PPC-SAFT(only (---); calculation by PSRK (-ש-

$\left.\mathrm{k}_{\mathrm{ij}}\right)(-$ - -); calculation by PSRK (-"-—) 
Figure 15 shows the relative deviation between the experimental Henry constant of hydrogen in oxygenated solvents and those calculated by using GC-PPC-SAFT. We observed that with a predictive method (i.e. group contribution) for both parameters $k_{\mathrm{ij}}$ and $\mathrm{l}_{\mathrm{ij}}$, we improve the overall predictive results in comparison with only predictive $\mathrm{k}_{\mathrm{ij}}$. For some solvents, the deviation is increased but for these only one or two data points exist and the deviations remain reasonable $(20 \%)$ in view of estimated experimental uncertainty.

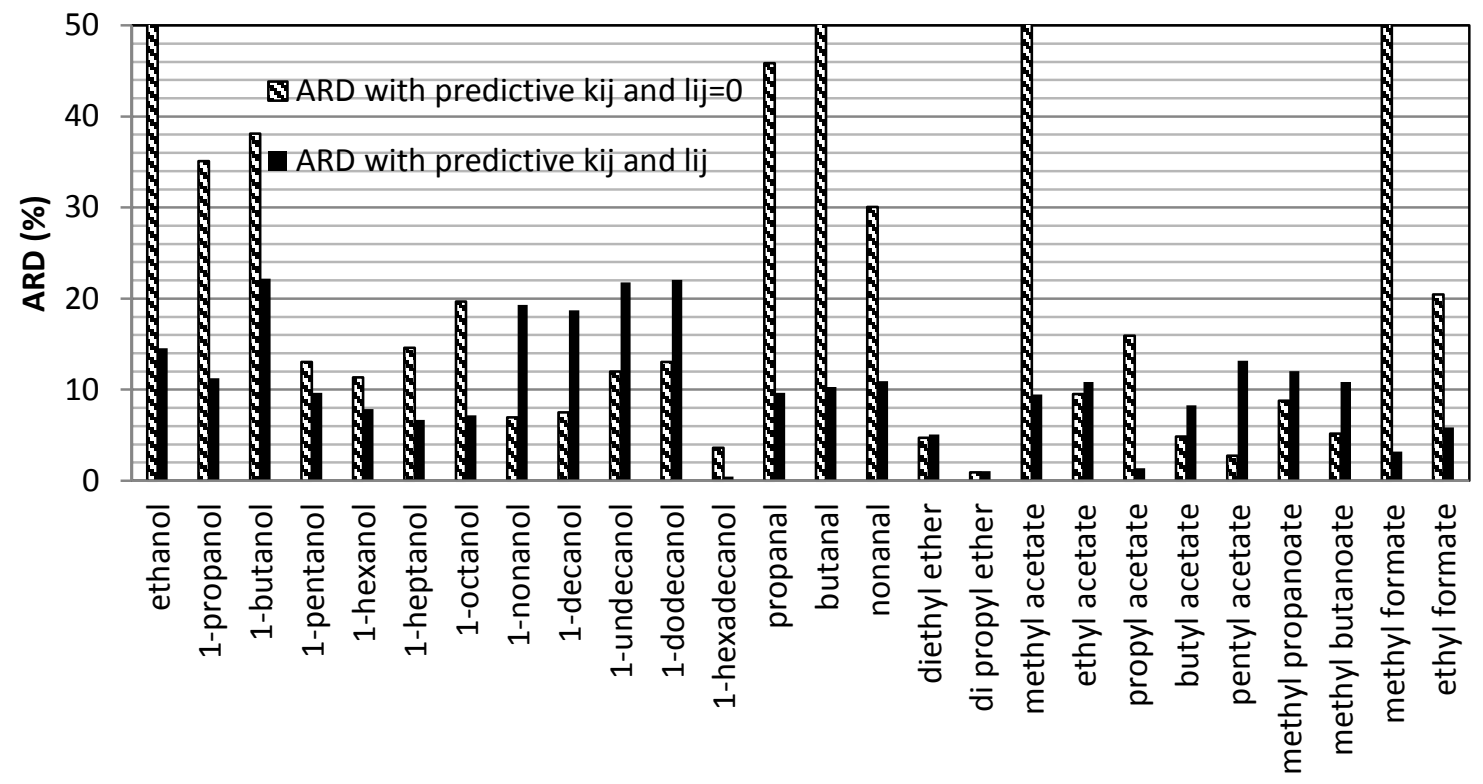

Figure 15: Relative deviation of Henry's constant of hydrogen in oxygenated solvents: using GC-PPC-SAFT with predictive $\mathrm{k}_{\mathrm{ij}}\left(\mathrm{l}_{\mathrm{ij}}=0\right)$ and with both predictive $\mathrm{k}_{\mathrm{ij}}, \mathrm{l}_{\mathrm{ij}}$

As an example, Figure 16 and Figure 17 show the experimental data and the calculated values by GC-PPC-SAFT (with both parameters $1_{i j}$ and $k_{i j}$ ) of Henry's constant for all oxygenated families investigated such as 1-alcohols, aldehydes, esters, ethers at $298.15 \mathrm{~K}$ as a function of molecular weight. In comparison between these values, we observe that with the nonadditive parameter, the GC-PPC-SAFT equation of state allows calculating the Henry constant of hydrogen in oxygen-bearing solvent with reasonable deviations. 


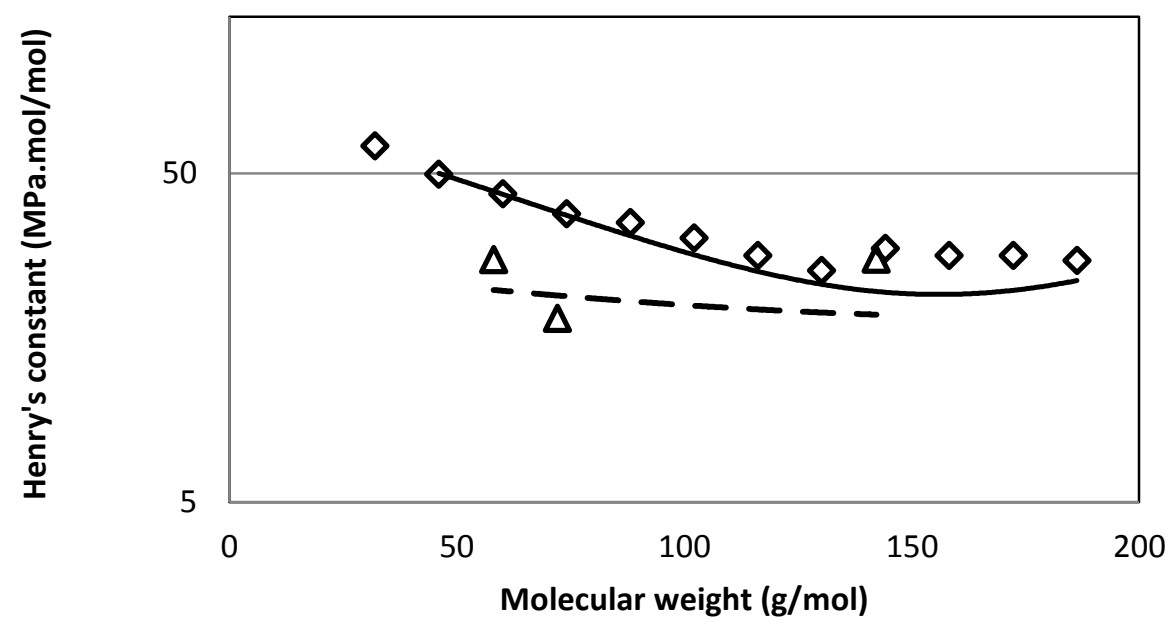

Figure 16: Experimental values and calculated values by GC-PPC-SAFT (with both $\mathrm{k}_{\mathrm{ij}}$ and $\mathrm{l}_{\mathrm{ij}}$ ) of Henry's constant of hydrogen in oxygenated compounds and in n-alkanes depending ontheir molar weight at $298.15 \mathrm{~K}$. Experimental data : $\mathrm{H}_{2} / 1$-alcohol $(\diamond), \mathrm{H}_{2} /$ aldehyde $(\Delta)$; GC-PPCSAFT: $\mathrm{H}_{2} / 1$-alcohol (一), $\mathrm{H}_{2} /$ aldehyde (-*)

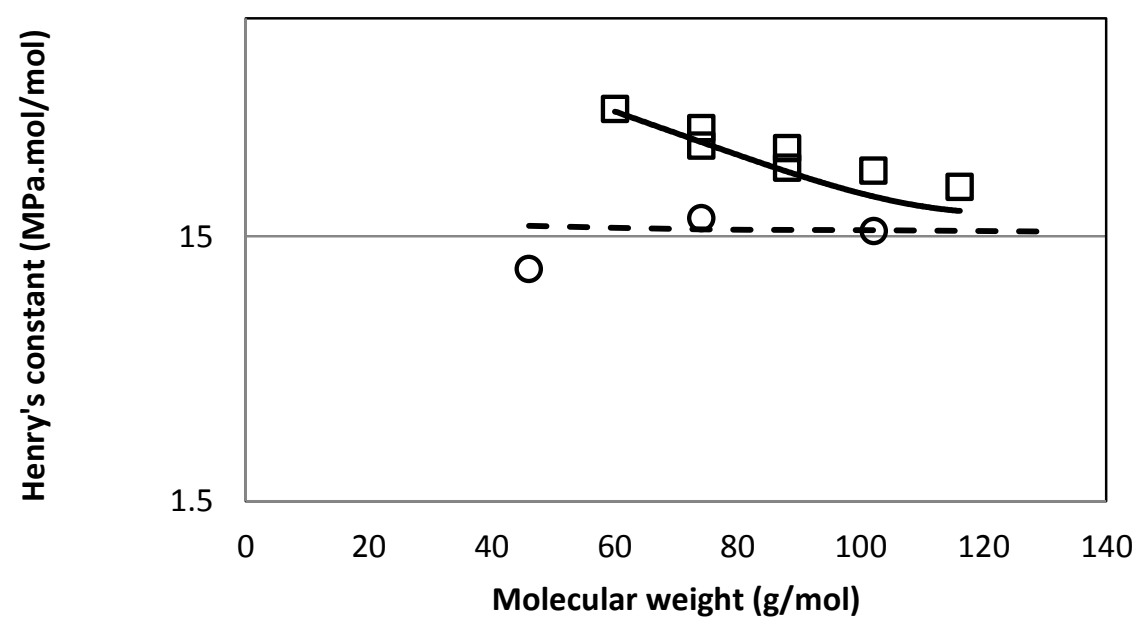

Figure 17: Experimental values and calculated values by GC-PPC-SAFT (with both $\mathrm{k}_{\mathrm{ij}}$ and $\mathrm{l}_{\mathrm{ij}}$ ) of Henry's constant of hydrogen in oxygenated compounds and in n-alkanes depending ontheir molar weight at $298.15 \mathrm{~K}$. Experimental data : $\mathrm{H}_{2} / \mathrm{n}$-alkane (+), $\mathrm{H}_{2} /$ ester ( $\left(\right.$ ) $; \mathrm{H}_{2} /$ ether (o); GC-

PPC-SAFT $\mathrm{H}_{2} /$ ester (一), $\mathrm{H}_{2} /$ ether (-・) 


\section{Conclusions}

The main target of this paper is to develop a physically-meaningful predictive approach as an extension to the GC-PPC-SAFT Equation of State, for the systems of hydrogen with oxygenated molecules.

At first, we used the GC-PPC-SAFT in a predictive way for computing the hydrogen solubility in oxygenated solvents. However, very high deviations are observed with respect to experimental Henry constants. The adjustment of $\mathrm{k}_{\mathrm{ij}}$ parameter on these Henry constants leads to negative values that are not acceptable in view of the predictive scheme.

Observing the relationship between free volume and hydrogen solubility led us to develop a new parameter that is based on repulsive interactions. Based on theoretical development of the non-additive term in the Square Well Equation of State, our equation of state was extended to systemswith non-additive diameters. A predictive scheme of the non-additive parameter using a group contribution is suggested and the values of this parameter depend on the polarity and association of the oxygen-bearing group. This new equation was tested with success to predict the solubility of hydrogen in oxygen-bearing components The deviations between the experimental Henry constants and those calculated by non-additive GC-PPC-SAFT are within the experimental uncertainty $(\sim 10 \%)$.

\section{Acknowledgements}

We would like to thank the financial support of Tuck Foundation through IFP Energies Nouvelles for this research.

\section{References}

[1] F. A. Agblevor, O. Mante, R. McClung, and S. T. Oyama, "Co-processing of standard gas oil and biocrude oil to hydrocarbon fuels," Biomass and Bioenergy, vol. 45, pp. 130-137, 2012.

[2] R. H. Venderbosch, A. R. Ardiyanti, J. Wildschut, A. Oasmaa, and H. J. Heeres, "Stabilization of biomass-derived pyrolysis oils," J. Chem. Technol. Biotechnol., vol. 85, no. 5, pp. 674-686, 2010.

[3] S. Asphaug, "Catalytic Hydrodeoxygenation of Bio-oils with Supported MoP-Catalysts," Norwergian University of Science and Technology, 2013. 
[4] D. R. Parapati, V. K. Guda, V. K. Penmetsa, P. H. Steele, and S. K. Tanneru, "Single Stage Hydroprocessing of Pyrolysis Oil in a Continuous Packed-Bed Reactor," Environ. Prog. Sustain. Energy, vol. 33, no. 3, pp. 726-731, 2014.

[5] M. Mourah, D. NguyenHuynh, J. P. Passarello, J. C. de Hemptinne, and P. Tobaly, "Modelling LLE and VLE of methanol+n-alkane series using GC-PC-SAFT with a group contribution kij," Fluid Phase Equilib., vol. 298, no. 1, pp. 154-168, 2010.

[6] E. Furimsky, "Review: Catalytic hydrodeoxygenation," Appl. Catal. A Gen., vol. 199, no. 2, pp. 147-190, Jun. 2000.

[7] R. Torres, J.-C. de Hemptinne, and I. Machin, "Improving the modeling of Hydrogen solubility in heavy oil cuts using an augmented Grayson Streed (AGS) Aprroach," Oil\&Gas Sci. Technol., vol. 68, no. 2, pp. 217-233, 2013.

[8] N. Ferrando and P. Ungerer, "Hydrogen/hydrocarbon phase equilibrium modelling with a cubic equation of state and a Monte Carlo method," Fluid Phase Equilib., vol. 254, no. 12, pp. 211-223, 2007.

[9] J. M. . Moysan, H. . Paradowski, and J. . Vidal, "Prediction of phase behaviour of gascontaining systems with cubic equations of state," Chem. Eng. Sci., vol. 41, no. 8, pp. 2069-2074, 1986.

[10] C. H. Twu, J. E. Coon, A. H. Harvey, and J. R. Cunningham, “An Approach for the Application of a Cubic Equation of State to Hydrogen - Hydrocarbon Systems," Ind. Eng. Chem. Res., vol. 35, no. 5, pp. 905-910, 1996.

[11] C. S. Su, "Improvement of predictive Soave-Redlich-Kwong (PSRK) equation of state for representing volumetric properties of carbon dioxide-expanded organic solvents," Chem. Eng. Res. Des., vol. 92, no. 11, pp. 2749-2757, 2014.

[12] C. Le Thi, S. Tamouza, J. Passarello, P. Tobaly, and J. De Hemptinne, "Modeling Phase Equilibrium of $\mathrm{H} 2+$ n-Alkane and $\mathrm{CO} 2+$ n-Alkane Binary Mixtures Using a Group Contribution Statistical Association Fluid Theory Equation of State (GC-SAFT-EOS) with a kij group contribution method," Ind. Eng. Chem. Res., vol. 45, pp. 6803-6810, 2006.

[13] L. J. Florusse, C. J. Peters, J. C. Pàmies, L. F. Vega, and H. Meijer, "Solubility of Hydrogen in Heavy n-Alkanes: Experiments and SAFT Modeling," AIChE J., vol. 49, no. 12, pp. 3260-3269, 2003.

[14] S. Tamouza, J.-P. Passarello, P. Tobaly, and J.-C. de Hemptinne, "Group contribution method with SAFT EOS applied to vapor liquid equilibria of various hydrocarbon series," Fluid Phase Equilib., vol. 222-223, pp. 67-76, Aug. 2004.

[15] D. Nguyen-huynh, J. Passarello, and P. Tobaly, "Modeling Phase Equilibria of Asymmetric Mixtures Using a Group-Contribution SAFT (GC-SAFT) with a kij 
correlation method based on London's theory. 1. Application to $\mathrm{CO} 2+$ n-alkane, methane + n-alkane and ethane + n-alkane systems," Ind. Eng. Chem. Res., vol. 47, pp. 8847-8858, 2008.

[16] D. NguyenHuynh, J.-P. Passarello, P. Tobaly, and J.-C. de Hemptinne, "Application of GC-SAFT EOS to polar systems using a segment approach," Fluid Phase Equilib., vol. 264, no. 1-2, pp. 62-75, Mar. 2008.

[17] T.-B. Nguyen, J.-C. de Hemptinne, B. Creton, and G. M. Kontogeorgis, "GC-PPC-SAFT Equation of State for VLE and LLE of Hydrocarbons and Oxygenated Compounds. Sensitivity Analysis," Ind. Eng. Chem. Res., vol. 52, no. 21, pp. 7014-7029, May 2013.

[18] D. NguyenHuynh, J.-P. Passarello, J.-C. de Hemptinne, F. Volle, and P. Tobaly, "Simultaneous modeling of VLE, LLE and VLLE of CO2 and 1, 2, 3 and 4 alkanol containing mixtures using GC-PPC-SAFT EOS," J. Supercrit. Fluids, vol. 95, pp. 146157, Nov. 2014.

[19] L. Grandjean, J. C. De Hemptinne, and R. Lugo, "Application of GC-PPC-SAFT EoS to ammonia and its mixtures," Fluid Phase Equilib., vol. 367, pp. 159-172, 2014.

[20] A. J. Haslam, A. Galindo, and G. Jackson, "Prediction of binary intermolecular potential parameters for use in modelling fluid mixtures," Fluid Phase Equilib., vol. 266, no. 1-2, pp. 105-128, 2008.

[21] T.-K.-H. Trinh, J.-P. Passarello, J.-C. de; Hemptinne, R. Lugo, and V.; Lachet, “A nonadditive repulsive contribution in an equation of state: The development for homonuclear square well chains equation of state validated against Monte Carlo simulation," $J$. Chemmical Phys., vol. 144, no. 12, 2016.

[22] A. O. Malakhov and V. V. Volkov, "Phase behavior of polymer mixtures with nonadditive hard-sphere potential," Polym. Sci. Ser. A, vol. 49, no. 6, pp. 745-756, 2007.

[23] D. Nguyen-huynh, "Modélisation thermodynamique de mélanges symétriques et asymétriques de composés polaires et/ou aromqtiques par GC-SAFT," Université Paris 13 Villetaneuse, 2008.

[24] J. Gross and G. Sadowski, "Perturbed-Chain SAFT: An Equation of State Based on a Perturbation Theory for Chain Molecules," Ind. Eng. Chem. Res., vol. 40, no. 4, pp. 12441260, Feb. 2001.

[25] T. Boublík, "Hard-Sphere Equation of State," J. Chem. Phys., vol. 53, no. 1, pp. 471-472, 1970.

[26] G. A. Mansoori, N. F. Carnahan, K. E. Starling, and T. W. Leland Jr, "Equilibrium Thermodynamic Properties of the Mixture of Hard Spheres," J. Chem. Phys., vol. 54, no. 4, p. 1523, 1971. 
[27] J. C. Mccoubrey and G. H. Hudson, "Intermolecular forces between unlike molecules: a more complete form of the combining rules," Trans. Faraday Soc, vol. 56, no. 2, pp. 761766, 1960.

[28] T.-B. Nguyen, J.-C. de Hemptinne, B. Creton, and G. M. Kontogeorgis, "Improving GCPPC-SAFT equation of state for LLE of hydrocarbons and oxygenated compounds with water," Fluid Phase Equilib., vol. 372, pp. 113-125, Jun. 2014.

[29] C. Held, A. Prinz, V. Wallmeyer, and G. Sadowski, "Measuring and modeling alcohol/salt systems," Chem. Eng. Sci., vol. 68, no. 1, pp. 328-339, 2012.

[30] S. S. Chen and A. Kreglewski, "Applications of the Augmented van der Waals Theory of Fluids.: I. Pure Fluids,” Berichte der Bunsengesellschaft für Phys. Chemie, vol. 81, no. 10, pp. 1048-1052, Oct. 1977.

[31] H. Twu and K. E. Gubbins, "Thermodynamics of polyatomic fluid mixtures-I: Theory," Chem. Eng. Sci., vol. 33, pp. 863-878, 1977.

[32] P. K. Jog and W. G. Chapman, "Application of Wertheim' s thermodynamic perturbation theory to dipolar hard sphere chains," Mol. Phys., vol. 97, no. 3, pp. 307-319, 1999.

[33] J. P. Wolbach and S. I. Sandler, "Using Molecular Orbital Calculations To Describe the Phase Behavior of Cross-associating Mixtures," Ind. Eng. Chem. Res., vol. 37, no. 8, pp. 2917-2928, 1998.

[34] T.-K.-H. Trinh, J.-C. de Hemptinne, R. Lugo, N. Ferrando, and J.-P. ; Passarello, "Hydrogen Solubility in Hydrocarbon and Oxygenated Organic Compounds," J. Chem. Eng. Data, vol. 61, no. 1, pp. 19-34, 2016.

[35] H. Gamsjäger, J. W. Lorimer, M. Salomon, D. G. Shaw, and R. P. T. Tomkins, “The IUPAC-NIST Solubility Data Series: A Guide to Preparation and Use of Compilations and Evaluations," J. Phys. Chem. Ref. Data, vol. 39, no. 2, p. 023101, 2010.

[36] A. Nann, C. Held, and G. Sadowski, "Liquid-Liquid Equilibria of 1-Butanol/Water/IL Systems," Ind. Eng. Chem. Res., vol. 52, no. 51, pp. 18472-18481, Dec. 2013.

[37] S. H. Huang and M. Radosz, "Equation of state for small, large, polydisperse and associating molecules," Ind. Eng. Chem. Res., vol. 29, no. 11, pp. 2284-2294, 1990.

[38] M. S. Wainwright, T. Ahn, D. L. Trimm, and N. W. Cant, "Solubility of Hydrogen in Alcohols and Esters," J. Chem. Eng. Data, vol. 24, no. 19, pp. 22-24, 1987.

[39] E. Brunner and W. Hultenschmidt, "Fluid mixtures at high pressures: VIII. Isothermal phase equilibria in the binary mixtures : ( ethanol + hydrogen or methane or ethane )," $J$. Chem. Thermodyn., vol. 22, no. 4, pp. 73-84, 1990. 
[40] J. Makranczy, L. Rusz, and K. Balog-Megyery, "Solubility of gases in normal alcohols," Hung. J. Ind. Chem., vol. 7, pp. 41-46, 1979.

[41] G. Just, "Solubility of Gases in Organic Solvents," Z. Phys. Chem. Stoechiom. Verwandtschaftsl., vol. 37, pp. 342-367, 1901.

[42] T. Katayama and T. Nitta, "Solubilities of Hydrogen and Nitrogen in Alcohols and nHexane," J. Chem. Eng. Data, vol. 21, no. 2, pp. 194-196, 1976.

[43] Purwanto, R. M. Deshpande, R. V. Chaudhari, and H. Delmas, "Solubility of Hydrogen, Carbon Monoxide, and 1-Octene in Various Solvents and Solvent Mixtures," J. Chem. Eng. Data, vol. 41, no. 6, pp. 1414-1417, Jan. 1996.

[44] V. Timofeev, "The Absorption of Hydrogen and Oxygen in Water and Alcohol," Z. Phys. Chem. Stoechiom. Verwandtschaftsl., vol. 6, pp. 141-152, 1890.

[45] E. B. Maxted and C. H. Moon, "The temperature coefficient of the solubility of hydrogen in organic solvents," Trans. Faraday Soc., vol. 32, pp. 769-775, 1936.

[46] P. Luehring and A. Schumpe, "Gas Solubilities (H2, He, N2, CO, O2, Ar, CO2,) in Organic Liquids at 293.2K," J. Chem. Eng. Data, vol. 34, pp. 250-252, 1989.

[47] A. H. Harvey, "Semiempirical correlation for Henry's constants over large temperature ranges," AIChE J., vol. 42, no. 5, pp. 1491-1494, May 1996.

[48] J. M. Moysan, H. Paradowski, and J. Vidal, "Predictions of phase behavior of gascontaining systems with cubic equation of state," Chem. Eng. Sci., vol. 41, no. 8, pp. 2069-2074, 1986.

[49] J. . Valderrama, L. . Cisternas, M. . Vergara, and M. . Bosse, "Binary interaction parameters in cubic equations of state for hydrogen-hydrocarbon mixtures," Chem. Eng. Sci., vol. 45, pp. 49-54, 1990.

[50] D. . NguyenHuynh, A. . Falaix, J.-P. ; Passarello, and J.-C. de Hemptinne, "Predicting VLE of heavy esters and their mixtures using PC-SAFT," Fluid Phase Equilib., vol. 264, no. 1-2, pp. 184-200, 2008.

[51] H. L. Cleve, R. Battino, J. H. Saylor, and D. P. M. Gross, "The solubility og Helium, Neon, Argon and Krypton in some hydrocarbon solvents," J. Phys. Chem., vol. 61, no. 8, pp. 1078-1082, 1957.

[52] J. L. . J. R. . N. F. D.-D. I. for P. P. O. R. V. W. . W. Y. . Y. and Giles, "Data Compilation of Pure Chemical Properties." [Online]. Available: http://www.aiche.org/dippr.

[53] T. Schnabel, J. Vrabec, and H. Hasse, "Unlike Lennard-Jones parameters for vapor-liquid equilibria," J. Mol. Liq., vol. 135, no. 1-3, pp. 170-178, 2007. 
[54] A. H. Harvey and J. M. Prausnitz, "The nonadditive hard sphere mixtures as a reference system in equation of state calculations," Fluid Phase Equiliba, vol. 48, pp. 197-208, 1989.

[55] M. A. Spackman, "Atom-atom potentials via electron gas theory," J. Chem. Phys., vol. 85 , no. 11, p. $6579,1986$.

[56] D. E. Williams and D. J. Craycroft, "Nonbonded H-H Repulsion Energy from ab Initio SCF Calculations of Methane, Water and Methanol dimers," J. Phys. Chem., vol. 91, no. 6, pp. 6365-6373, 1987.

[57] B. Zhang, S. Liang, and Y. Lu, "Calculating thermodynamic properties from perturbation theory II . An analytic representation for the square-well chain fluid," Fluid Phase Equilib., vol. 180, pp. 183-194, 2001.

[58] F. W. Tavares, J. Chang, and S. I. Sandler, "Equation of state for the square-well chain fluid based on the dimer version of Wertheim's perturbation theory," Mol. Phys., vol. 86, no. 6, pp. 1451-1471, 1995.

[59] J. Chang and S. I. Sandler, "The correlation functions of hard-sphere chain fluids: Comparison of the Wertheim integral equation theory with the Monte Carlo simulation," J. Chem. Phys., vol. 102, no. 1, pp. 437-449, 1995.

[60] J. a. Porter, S. V. Fridrikh, and J. E. G. Lipson, "Square-well chain fluids: The thermodynamic properties of hexamers, octamers, and hexadecamers," J. Chem. Phys., vol. 119, no. 7, pp. 3883-3890, 2003.

[61] M. P. Taylor, J. Luettmer-Strathmann, and J. E. G. Lipson, "Structure and phase behavior of square-well dimer fluids," J. Chem. Phys., vol. 114, no. 13, pp. 5654-5662, 2001.

[62] S. V. Fridrikh and J. E. G. Lipson, "Square-well fluids: The statistical and thermodynamic properties of short chains," J. Chem. Phys., vol. 116, no. 19, pp. 8483-8491, 2002.

[63] J. Largo, J. R. Solana, S. B. Yuste, and A. Santos, "Pair correlation function of shortranged square-well fluids.," J. Chem. Phys., vol. 122, no. 8, pp. 845101-8451012, 2005.

[64] J. G. Kirkwood, E. K. Maun, and B. J. Alder, "Radial distribution functions and the equation of state of a fluid composed of rigid spherical molecules," J. Chem. Phys., vol. 18, no. 8, pp. 1040-1047, 1950.

[65] K. U. Co, J. J. Kozak, and K. D. Luks, "Solutions of the Yvon-Born-Green equation for the square-well fluid at very high densities," J. Chem. Phys., vol. 65, no. 6, pp. 23272332, 1976. 
[66] W. W. Lincoln, J. J. Kozak, and K. D. Luks, "Properties of solutions to the Yvon-BornGreen equation for the square-well fluid," J. Chem. Phys., vol. 62, no. 6, pp. 2171-2182, 1975.

[67] J. G. Kirkwood, V. A. Lewinson, and B. J. Alder, "Radial distribution functions and the equation of state of fluids composed of molecules interacting according to the LennardJones potential," J. Chem. Phys., vol. 20, no. 6, pp. 929-938, 1952.

[68] A. A. Broyle, "Radial Distribution Functions from the Born-Green Integral Equation," J.Chem.Phys, vol. 33, no. 2, pp. 456-458, 1960.

[69] D. Nguyen-huynh, J. De Hemptinne, R. Lugo, J. Passarello, and P. Tobaly, "Modeling Liquid À Liquid and Liquid À Vapor Equilibria of Binary Systems Containing Water with an Alkane, an Aromatic Hydrocarbon, an Alcohol or a Gas ( Methane, Ethane, CO2 or H2S ), Using Group Contribution Polar Perturbed-Chain Statistical Associat," Ind. Eng. Chem. Res., vol. 50, pp. 7467-7483, 2011.

[70] R. L. Rowley, W. V. Wilding, A. Congote, and N. F. Giles, "The use of database influence factors to maintain currency in an evaluated chemical database," Int. J. Thermophys., vol. 31, no. 4-5, pp. 860-874, 2010.

[71] J. C. Gjaldbaek and H. Niemann, "The solubility of Nitrogen, Argon and Ethane in Alcohols and water," Acta Chem. Scand., vol. 12, no. 5, pp. 1015-1023, 1958.

[72] M. Yaacobi and A. Ben-Naim, "Solvophobic Interaction," J. Phys. Chem., vol. 78, no. 2, pp. 175-178, 1972.

[73] K. Suzuki, H. Sue, M. Itou, R. L. Smith, H. Inomata, K. Arai, and S. Saito, "Isothermal Vapor-Liquid Equilibrium Data for Binary Systems at High Pressures: Carbon DioxideMethanol, Carbon Dioxide-Ethanol, Carbon Dioxide-I-Propanol, Methane-Ethanol, Methane-I-Propanol, Ethane-Ethanol, and Ethane-I-Propanol Systems," J. Chem. Eng. Data, vol. 35, no. 8, pp. 63-66, 1990.

[74] D. Kodama, H. Tanaka, and M. Kato, "High Pressure Phase Equilibrium for Ethane + 1Propanol at 314.15 K," J. Chem. Eng. Data, vol. 46, no. 5, pp. 1280-1282, 2001.

[75] R. . Jimenez-Gallegos, L. A. . Galicia-Luna, C. . Bouchot, L. E. . Camacho-Camacho, and O. . Elizalde-Solis, "Experimental Determination and Correlation of Phase Equilibria for the Ethane + 1-Propanol and Propane + 1-Propanol Systems," J. Chem. Eng. Data, vol. 51, no. 5, pp. 1629-1633, 2006.

[76] S. Bo, R. Battino, and E. Wilhelm, "Solubility of Gases in Liquids. 19. Solubility of He, $\mathrm{Ne}, \mathrm{Ar}, \mathrm{Kr}, \mathrm{Xe}, \mathrm{N} 2, \mathrm{O} 2, \mathrm{CH} 4, \mathrm{CF} 4$, and SF6 in Normal 1-Alkanols n-CnH2n+1OH $(1<=\mathrm{n}<=11)$ at 298.15 K," J. Chem. Eng. Data, vol. 38, no. 4, pp. 611-616, 1993.

[77] D. R. Lide, CRC Handbook of Chemistry and Physics, CRC Press. New York, USA, 2005. 
[78] I. R. Krichevskii and G. D. Efremova, "Phase and volume relations in liquid-gas systems at high pressures. III.," Zh. Fiz. Khim., vol. 25, pp. 577-583, 1951.

[79] A. . Michels and J. de Graaff, W.; van der Somme, "Gas-Liquid Phase Equilibrium in the System Methanol - Hydrogen,” Appl. Sci. Res., vol. 4, no. 5, pp. 105-108, 1953.

[80] E. Brunner, "Solubility of Hydrogen in Alcohols," Phys. Chem., vol. 83, no. 7, pp. 715$721,1979$.

[81] J. Horiuti, "On the Solubility of Gas and Coefficient of Dilatation by Absorption," Sci. Pap. Inst. Phys. Chem. Res. Jpn., vol. 17, no. 341, pp. 125-256, 1931.

[82] I. I. Vasileva, A. A. Naumova, A. A. Polyakov, T. N. Tyvina, and V. V. Fokina, "Composition and molar volume of hydrogen, nitrogen and methane solutions in propionic aldehyde,” Zh. Prikl. Khim., vol. 60, no. 2, pp. 408-410, 1987.

[83] D. Nguyen-huynh, T. K. S. Tran, S. Tamouza, J. Passarello, and P. Tobaly, "Modeling Phase Equilibria of Asymmetric Mixtures Using a Group-Contribution SAFT (GC-SAFT) with a kij correlation method based on London's theory. 1. Application to binary mixture containing aromatic hydrocarbons, n-alkanes, CO2, N2 and H2S," Ind. Eng. Chem. Res., vol. 47, no. 22, pp. 8859-8868, 2008.

[84] J. Rozmus, J.-C. de Hemptinne, N. Ferrando, and P. Mougin, "Long chain multifunctional molecules with GC-PPC-SAFT: Limits of data and model," Fluid Phase Equilib., vol. 329, pp. 78-85, Sep. 2012.

[85] J.-C. de H. G. Buret, “Equation d'état SAFT: amélioration des performance,” 2009.

[86] M. L. Michelsen and J. Mollerup, Thermodynamic Models: Fundamentals and Computational Aspects. 2004.

\section{Appendix A: Parameters for the use of GC-PCC-SAFT}

We have used the hydrogen parameters from the work of Tran .T. K.S et $a^{31}$. For binary mixture containing small molecules such as methanol, acetone,..., the pure component parameters are used. All these parameters are available in Table 4. The parameters of the alkyl groups and oxygenated groups like $\mathrm{OH}, \mathrm{CHO}, \mathrm{C}=\mathrm{O}, \mathrm{O}-$, ... were developed by Nguyen Huynh et al.[23]. In addition, we used the group parameters for diols as developed by Rozmus at al. ${ }^{32}$. In their study, an expression was proposed to calculate the cross self-association volume of $\mathrm{OH}$ group: 


$$
\kappa^{A_{\alpha} B_{\beta}}=\kappa_{0}^{A_{\alpha} B_{\beta}}+\kappa_{1}^{A_{\alpha} B_{\beta}}\left(1-\frac{2}{n}\right)(A .1)
$$

Where $\kappa_{0}^{A_{\alpha} B_{\beta}}=0.00885, \kappa_{1}^{A_{\alpha} B_{\beta}}=0.006374$, the original value of $\kappa^{A_{\alpha} B_{\beta}}$ of alkanol group and $\mathrm{n}$ is the distance (number of carbon) between two associative groups. 
TableA.1.: Group contribution parameters for alkanes and oxygenated compounds for the use of GC-PPC-SAFT

\begin{tabular}{|c|c|c|c|c|c|c|c|c|c|c|c|c|}
\hline & Group & $\mathbf{\varepsilon} / \mathbf{k}(\mathbf{K})$ & $\sigma(\AA)$ & $\mu$ & $\mathbf{x}_{\mathrm{p}}^{\mu} \mathrm{m}$ & $\mathbf{Q}$ & $\mathbf{x}_{\mathrm{p}}^{\mathbf{Q}} \mathbf{m}$ & $\varepsilon^{A_{\alpha} B_{\beta}} / \boldsymbol{k}(\mathbf{K})$ & $\kappa^{A_{\alpha} B}$ & $\mathbf{J}(\mathrm{eV})$ & $\mathbf{R} * *$ & Reference \\
\hline \multirow[t]{2}{*}{ alkanes } & $\mathrm{CH} 3$ & 189.9628 & 3.4872 & 0 & 0 & 0 & 0 & 0 & 0 & 22.755 & 0.7866 & Mourah et al.[5] \\
\hline & $\mathrm{CH} 2$ & 261.0866 & 3.9308 & 0 & 0 & 0 & 0 & 0 & 0 & 6.254 & 0.3821 & Mourah et al.[5] \\
\hline alkanol & $\mathrm{OH}$ & 307.5094 & 2.8138 & 1.7 & 0.5 & 0 & 0 & 2143.3 & 0.0088 & 28.008 & 0.8318 & $\begin{array}{l}\text { NguyenHuynh et } \\
\text { al.[18] }\end{array}$ \\
\hline diol & $\mathrm{OH}$ diol & 307.5094 & 2.8138 & 1.7 & 0.5 & 0 & 0 & 2143.3 & $(*)$ & 28.008 & - & Rozmus et al.[84] \\
\hline aldehyde & $\mathrm{CHO}$ & 397.6683 & 3.8538 & 3.1614 & 0.6 & 0 & 0 & 2143.3 & 0.0088 & - & 0.7180 & NguyenHuynh[23] \\
\hline ketone & $\mathrm{C}=\mathrm{O}$ & 480.7307 & 3.7495 & 2.7 & 0.57 & 0 & 0 & 2143.3 & 0.0088 & - & $\begin{array}{l}\mathrm{R}_{2}=0.5154 \\
\mathrm{R}_{3}=0.4539\end{array}$ & NguyenHuynh[23] \\
\hline ether & $-\mathrm{O}-$ & 280.9593 & 3.5764 & 1.2 & 1.2 & 0 & 0 & 2143.3 & 0.0088 & - & 0.5465 & NguyenHuynh[23] \\
\hline ester & $\mathrm{COO}$ & 362.8198 & 3.3447 & 2.0177 & 1.15 & 0 & 0 & 2143.3 & 0.0088 & - & $\begin{array}{l}\mathrm{R}_{2}=0.8273 \\
\mathrm{R}_{3}=0.8116\end{array}$ & NguyenHuynh[23] \\
\hline formate & $\mathrm{HCOO}$ & 289.5501 & 3.3765 & 1.9 & 1.2041 & 0 & 0 & 2143.2976 & 0.008847 & - & 1.1360849 & NguyenHuynh[23] \\
\hline $\mathrm{H}_{2}^{\#}$ & & 26.627 & 2.906 & 0 & 0 & 0 & 0 & 0 & 0 & 15 & 1.112 & $\begin{array}{l}\text { NguyenHuynh } \\
\text { al.[83] }\end{array}$ \\
\hline Methanol $^{\#}$ & & 166.8 & 2.6321 & 1.7 & 0.35 & 0 & 0 & 2069.09 & 0.2373 & 15.55 & 2.8271 & $\begin{array}{l}\text { NguyenHuynh } \\
\text { al.[83] }\end{array}$ \\
\hline Ethanol $^{\#}$ & & 191.6306 & 2.9178 & 1.7 & 0.2 & 0 & 0 & 2125.522 & 0.094 & 12.76415 & 3.072205 & $\begin{array}{l}\text { NguyenHuynh } \\
\text { al.[83] }\end{array}$ \\
\hline Acetone $^{\#}$ & & 258.8688 & 3.5747 & 2.72 & 0.57 & 0 & 0 & 2143.3 & 0.0088 & - & 2.0886 & $\begin{array}{l}\text { NguyenHuynh } \\
\text { al.[83] }\end{array}$ \\
\hline Methane $^{\#}$ & & 147.4177 & 3.6582 & 0 & 0 & 0 & 0 & 0 & 0 & 12.61 & 1.033354 & NguyenHuynh[23] \\
\hline Ethane $^{\#}$ & & 189 & 3.5098 & 0 & 0 & 0 & 0 & 0 & 0 & 11.52 & 1.6364 & NguyenHuynh[23] \\
\hline
\end{tabular}




\begin{tabular}{|l|l|l|l|l|l|l|l|l|l|l|l|l|}
\hline $\mathrm{CO}^{\#}$ & & 95.25 & 3.3979 & 2 & 0.45 & 2 & 0.45 & 0 & 0 & 18 & 1.17 \\
\hline $\mathrm{H}_{2} \mathrm{~S}^{\#}$ & & 225.05 & 3.4161 & 0 & 0 & 0 & 0 & 449.71 & 0.0947 & 10.45 & 1.3018 & NguyenHuynh[23] \\
\hline $\mathrm{NH}_{3}{ }^{\#}$ & & 204.6311 & 3.2386 & 1.469 & 1.3976 & 0 & 0 & 646.3276 & 0.00597 & 0 & 1.1158 & Grandjean et al.[19] \\
\hline
\end{tabular}

*: value of $\kappa^{A_{\alpha} B_{\beta}}$ depends on the number of carbon in a diol and is calculated by the equation (IV.A.1)

**: for some groups the $\mathrm{R}$ parameter depends on its position within the molecule (indicated here as $\mathrm{R}_{2}$ and $\mathrm{R}_{3}$ ). For details see the original articles[84], [69].

\#: some small molecules are considered as consisting of a single group 
Appendix B: Experimental data in the literature[70]

Table B.1. : Experimental Henry constant of ethane in oxygenated solvent

\begin{tabular}{|c|c|c|}
\hline Solvent used & Temperature (K) & Henry constant (MPa) \\
\hline \multirow[t]{6}{*}{ propanal } & 293.2 & 7.78 \\
\hline & 313.2 & 9.66 \\
\hline & 333.2 & 12.15 \\
\hline & 353.2 & 13.62 \\
\hline & 373.2 & \begin{tabular}{|l|l|}
16.3 \\
\end{tabular} \\
\hline & 393.2 & 18.29 \\
\hline \multirow[t]{11}{*}{ acetone } & 298.15 & 12.05 \\
\hline & 298.15 & 10.28 \\
\hline & 313.15 & 12.46 \\
\hline & 308.15 & 11.85 \\
\hline & 303.15 & 11.15 \\
\hline & 298.15 & 10.51 \\
\hline & 293.15 & 9.91 \\
\hline & 288.15 & 9.35 \\
\hline & 283.15 & 8.76 \\
\hline & 278.15 & 8.23 \\
\hline & 273.15 & 7.68 \\
\hline Diethyl ether & 298.15 & 3.37 \\
\hline \multirow[t]{8}{*}{ 1,2-ethanediol } & 283.2 & 196.4 \\
\hline & 293.2 & 230.1 \\
\hline & 303.2 & 270.3 \\
\hline & 298.15 & 172.3 \\
\hline & 323.15 & 218.2 \\
\hline & 348.15 & 261.7 \\
\hline & 373.15 & 281 \\
\hline & 398.15 & 296.1 \\
\hline
\end{tabular}




\begin{tabular}{|c|c|c|}
\hline & 298.16 & 189.83 \\
\hline & 298.16 & 188.25 \\
\hline & 298.16 & 189.04 \\
\hline & 308.14 & 207.19 \\
\hline & 308.14 & 207.62 \\
\hline & 298.15 & 62.82 \\
\hline \multirow[t]{10}{*}{ Methyl acetate } & 298.15 & 13.33 \\
\hline & 313.15 & 11.4 \\
\hline & 308.15 & 10.77 \\
\hline & 303.15 & 10.2 \\
\hline & 298.15 & 9.67 \\
\hline & 293.15 & 9.11 \\
\hline & 288.15 & 8.6 \\
\hline & 283.15 & 8.07 \\
\hline & 278.15 & 7.58 \\
\hline & 273.15 & 7.12 \\
\hline \multirow[t]{4}{*}{ Ethyl acetate } & 298.15 & 5.12 \\
\hline & 295.15 & 8.21 \\
\hline & 303.15 & 8.4 \\
\hline & 313.15 & 8.72 \\
\hline \multirow[t]{3}{*}{ Pentyl acetate } & 295.15 & 4.71 \\
\hline & 303.15 & 5.06 \\
\hline & 323.15 & 6.16 \\
\hline
\end{tabular}

\section{Table B.2: Experimental Henry constant of methane in oxygenated solvent}

\begin{tabular}{|l|l|l|}
\hline Solvent used & Temperature (K) & Henry constant $(\mathrm{MPa})$ \\
\hline Dimethyl ether & 282.9 & 21.83 \\
\hline
\end{tabular}




\begin{tabular}{|c|c|c|}
\hline & 313.3 & 21.85 \\
\hline & 343.3 & 24.43 \\
\hline & 283.2 & 21.7 \\
\hline Diethyl ether & 284.3 & 19.18 \\
\hline & 313.3 & 22.48 \\
\hline & 342.5 & 23.97 \\
\hline & 293.15 & 21.87 \\
\hline & 273.15 & 19.6 \\
\hline & 252.55 & 16.95 \\
\hline & 231.85 & 13.84 \\
\hline & 211.55 & 10.92 \\
\hline & 196.45 & 8.57 \\
\hline & 192.75 & 8.07 \\
\hline & 273.15 & 21.26 \\
\hline & 283.15 & 22.51 \\
\hline n-propyl ether & 293.15 & 83.94 \\
\hline & 298.15 & 77.56 \\
\hline 1,2-ethanediol & 298.15 & 644.2 \\
\hline & 323.15 & 672.7 \\
\hline & 348.15 & 680.2 \\
\hline & 373.15 & 670.6 \\
\hline & 398.15 & 630.3 \\
\hline & 283.2 & 687.3 \\
\hline & 293.2 & 698.7 \\
\hline & 303.2 & 725.1 \\
\hline & 323.15 & 720.4 \\
\hline & 373.15 & 700.9 \\
\hline & 398.15 & 621.8 \\
\hline
\end{tabular}




\begin{tabular}{|c|c|c|}
\hline & 303.15 & \begin{tabular}{|l|l|}
694.7 \\
\end{tabular} \\
\hline & 323.15 & 660 \\
\hline & 373.15 & 526.8 \\
\hline & 398.15 & 471.5 \\
\hline & 423.15 & 419.2 \\
\hline & 298.15 & 5877 \\
\hline & & \\
\hline & 303.15 & 968.6 \\
\hline & 323.15 & 818.4 \\
\hline & 373.15 & \begin{tabular}{|l|}
567.3 \\
\end{tabular} \\
\hline & 398.15 & 481.4 \\
\hline & 423.15 & 415.8 \\
\hline & 298.15 & 656.3 \\
\hline & 323.15 & 665.1 \\
\hline & 348.15 & 682.3 \\
\hline & 373.15 & 675.5 \\
\hline & 398.15 & 636.9 \\
\hline 1,4-butanediol & 303.15 & 599 \\
\hline & 323.15 & 561.2 \\
\hline & 373.15 & 497.7 \\
\hline & 398.15 & 433.5 \\
\hline & 423.15 & 376 \\
\hline & 303.15 & 691.3 \\
\hline & 323.15 & 639.7 \\
\hline & 373.15 & 534.2 \\
\hline & 398.15 & 491.8 \\
\hline & 423.15 & 460.4 \\
\hline acetone & 183.15 & 14.3 \\
\hline & 213.15 & 18.43 \\
\hline
\end{tabular}




\begin{tabular}{|c|c|c|}
\hline & 233.15 & 21.85 \\
\hline & 253.15 & 22.91 \\
\hline & 273.15 & 26.15 \\
\hline & 293.15 & 26.88 \\
\hline & 291.15 & 52.49 \\
\hline & 291.15 & 52.4 \\
\hline & 298.15 & 54.44 \\
\hline & 298.15 & 54.83 \\
\hline & 310.15 & 55.24 \\
\hline & 310.15 & 55.44 \\
\hline & 298.15 & 82.12 \\
\hline & 293.15 & 73.98 \\
\hline & 298.15 & 66.42 \\
\hline & 283.15 & 62.09 \\
\hline & 278.15 & 57.69 \\
\hline & 313.15 & 56.62 \\
\hline & 293.15 & 54.03 \\
\hline & 273.15 & 51.2 \\
\hline & 251.35 & 46.38 \\
\hline & 232.15 & 41.15 \\
\hline & 212.55 & 34.78 \\
\hline & 196.55 & 28.91 \\
\hline Acetic acid & 298.15 & 169.3 \\
\hline & 323.15 & 176.8 \\
\hline & 348.15 & 193.5 \\
\hline Ethyl acetate & 303.52 & 38.61 \\
\hline & 333.14 & 40.62 \\
\hline & 363.18 & 41.7 \\
\hline Methyl acetate & 313.15 & 53.42 \\
\hline & 293.15 & 51.07 \\
\hline
\end{tabular}




\begin{tabular}{|l|l|l|}
\hline & 273.15 & 48.59 \\
\hline & 252.75 & 45.13 \\
\hline & 231.55 & 40.75 \\
\hline & 212.55 & 35.62 \\
\hline & 196.55 & 30.67 \\
\hline Ethyl formate & 303.48 & 48.57 \\
\hline & 333.15 & 50.47 \\
\hline & 363.18 & 50.95 \\
\hline
\end{tabular}

\section{Appendix C: Derivatives of the free energy of non-additive term}

The PPC-SAFT equation is expressed from the reduced residual free energy $F=$ $\frac{A^{r e s}(T, V, N)}{R T}$ with temperature variables, volume and number of moles of each component[85].

The thermodynamicproperties are then calculated according to the formula proposed by Michelsen[86]:

$>$ Relation between the pressure and the free energy :

$$
\begin{gathered}
\left.P=-R T \frac{\partial F}{\partial V}\right]_{T, N}+\frac{N R T}{V}(C .1) \\
\left.\frac{\partial P}{\partial V}=-R T \frac{\partial^{2} F}{\partial V^{2}}\right]_{T, N}-\frac{N R T}{V^{2}}(C .2)
\end{gathered}
$$

Relation between the fugacity coefficient and the free energy :

$$
\begin{aligned}
& \ln \left(\varphi_{i}\right)=\left(\frac{\partial F}{\partial N_{i}}\right)_{T, V, N_{j}}-\ln \left(\frac{P V}{N R T}\right) \\
& \left.\frac{\partial \ln \left(\varphi_{i}\right)}{\partial N_{j}}=\frac{\partial^{2} F}{\partial N_{i} \partial N_{j}}\right]_{T, V, N_{k \neq i, j}}+\frac{1}{N}
\end{aligned}
$$

Relation between residual entropy and the free energy : 


$$
\left.\frac{S^{r e s}(T, V, N)}{R}=-T \frac{\partial F}{\partial T}\right]_{V, N}-F
$$

Relation between residual enthalpy and the free energy :

$$
H^{r e s}(T, P, N)=A^{r e s}(T, V, N)+T S^{r e s}(T, V, N)+P V-N R T(C .6)
$$

In the new version of PC-SAFT equation of state, we adjust a term into the sum which is presented in Equation (1):

$$
A^{\text {res }}=\left(m A^{h s}+A^{\text {chain }}\right)+A^{d i s p}+A^{a s s o c}+A^{\text {multi-polaire }}+A^{N A H S}
$$

Where the last term $\mathrm{A}^{\mathrm{NAHS}}$ originates from the equation (7) that is written here, but with the variables $n_{i}$ (number of mole of component $\left.i\right), V$ (total volume) and $T$ (temperature):

$$
\begin{aligned}
& \frac{A^{p e r t}}{N k T}=-2 \pi \rho \\
& \qquad \begin{array}{l}
\quad \sum_{i} \sum_{j} x_{i} x_{j} m_{i} m_{j} \sigma_{i j}^{r e f 3} l_{i j}\left[g_{i j}^{r e f}\left(\sigma_{i j}^{r e f+}\right)-\lambda^{3} g_{i j}^{r e f}\left(\lambda \sigma_{i j}^{r e f-}\right)\right. \\
\left.+e^{-\beta \varepsilon_{i j} \lambda^{3} g_{i j}^{r e f}}\left(\lambda \sigma_{i j}^{r e f-}\right)\right] \text { (C.8) }
\end{array}
\end{aligned}
$$

Where $\rho=\frac{N}{V}=\frac{\sum n_{l} \times N_{A v}}{V}$

$\mathrm{N}$ is total number of molecules in the investigated system

$\mathrm{V}$ is total volume

We have $x_{i}=\frac{n_{i}}{\sum n_{l}}$ and $x_{j}=\frac{n_{j}}{\sum n_{l}}$ with $n_{l}$ is the number of moles of component 1 in the mixture.

We rewrite:

$$
\frac{A^{p e r t}}{N k T}=F^{*}=-2 \pi \frac{\sum n_{l} \times N_{A v}}{V} \times \sum_{i} \sum_{j} \frac{m_{i} n_{i} m_{j} n_{j}}{\left(\sum n_{l}\right)^{2}} \times d_{i j}^{3} l_{i j} g_{i j}
$$


Where $g_{i j}=g_{i j}^{r e f}\left(\sigma_{i j}^{r e f+}\right)-\lambda^{3} g_{i j}^{r e f}\left(\lambda \sigma_{i j}^{r e f-}\right)+e^{-\beta \varepsilon_{i j}} \lambda^{3} g_{i j}^{r e f}\left(\lambda \sigma_{i j}^{r e f-}\right)$

Where $d_{i j}=\sigma_{i j}^{r e f}$ (note that in the PC-SAFT, $d_{i j}$ is the temperature - dependent diameter.

Equation (IV.C.8) becomes:

$$
\frac{A^{p e r t}}{N k T}=-2 \pi \frac{N_{A v}}{V} \times \sum_{i} \sum_{j} \frac{m_{i} n_{i} m_{j} n_{j}}{\sum n_{l}} \times d_{i j}^{3} l_{i j} g_{i j}
$$

In order to calculate the thermodynamic properties, we need to determine $=\frac{A}{R T}$. We have here $F^{*}=\frac{A}{N k T}$ with $N=\sum n_{l} \times N_{A v}$. Indeed,

$$
\frac{A}{R T}=\frac{A}{N_{A v} k T}=\frac{A}{\sum n_{l} \times N_{A v} k T} \times \sum n_{l}=\frac{A}{N k T} \times \sum n_{l}
$$

Therefore:

$$
\begin{gathered}
\frac{A}{R T}=2 \pi \frac{N_{A v}}{V} \times \sum_{i} \sum_{j} \frac{m_{i} n_{i} m_{j} n_{j}}{\sum n_{l}} \times d_{i j}^{3} l_{i j} g_{i j} \times \sum n_{l} \\
F=\frac{A}{R T}=2 \pi \frac{N_{A v}}{V} \times \sum_{i} \sum_{j} m_{i} n_{i} m_{j} n_{j} \times d_{i j}^{3} l_{i j} g_{i j}
\end{gathered}
$$

To obtain the derivatives of $\mathrm{F}$, firstly we need to derive the inter-segment distribution function $g_{\mathrm{ij}}$

First derivative of $\mathrm{g}(\mathrm{r})$ as a function of $(\mathrm{V})$

$$
\frac{\partial g_{i j}}{\partial V}=\frac{\partial g_{i j}}{\partial \eta} \times \frac{\partial \eta}{\partial V}
$$

Where

$$
\frac{\partial g_{i j}}{\partial \eta}=\sum_{p=0}^{4} \sum_{q=1}^{4} a_{p q}\left(\beta \varepsilon_{i j}\right)^{p} \frac{\eta^{q-2}}{(1-\eta)^{q+1}}(\eta+q-1)
$$




$$
\frac{\partial \eta}{\partial V}=-\frac{\pi}{6} \times N_{A v} \times \frac{N}{V^{2}} \sum_{i=1}^{n} x_{i} m_{i} d_{i i}^{3}
$$

Second derivative of $\mathrm{g}(\mathrm{r})$ as a function of $\mathrm{V}$

$$
\begin{aligned}
& \frac{\partial^{2} g_{i j}}{\partial V^{2}}=\frac{\partial\left(\frac{\partial g_{i j}}{\partial V}\right)}{\partial V}=\frac{\partial\left(\frac{\partial g_{i j}}{\partial \eta} \times \frac{\partial \eta}{\partial V}\right)}{\partial V}=\frac{\partial^{2} g_{i j}}{\partial \eta \partial V} \times \frac{\partial \eta}{\partial V}+\frac{\partial g_{i j}}{\partial \eta} \times \frac{\partial^{2} \eta}{\partial V^{2}} \\
& =\frac{\partial\left(\frac{\partial g_{i j}}{\partial \eta}\right)}{\partial \eta} \times \frac{\partial \eta}{\partial V} \times \frac{\partial \eta}{\partial V}+\frac{\partial g_{i j}}{\partial \eta} \times \frac{\partial^{2} \eta}{\partial V^{2}} \\
& =\frac{\partial^{2} g_{i j}}{\partial \eta^{2}} \times\left(\frac{\partial \eta}{\partial V}\right)^{2}+\frac{\partial g_{i j}}{\partial \eta} \times \frac{\partial^{2} \eta}{\partial V^{2}}
\end{aligned}
$$

Where

$$
\begin{aligned}
\frac{\partial^{2} g_{i j}}{\partial \eta^{2}}=\sum_{p=0}^{4} \sum_{q=1}^{4} a_{p q}\left(\frac{\varepsilon}{k T}\right)^{p} \frac{\eta^{q-2}}{(1-\eta)^{q+1}}\left[\frac{1}{\eta}[(\eta+q-1)(q-2)+\eta]+\frac{1}{1-\eta}(\eta+q-1)(q\right. \\
+1)](C .19)
\end{aligned}
$$

$>$ First derivative of $\mathrm{g}(\mathrm{r})$ as a function of $\mathrm{T}$

$$
\frac{\partial g_{i j}}{\partial T}=\frac{\partial g_{i j}}{\partial \eta} \times \frac{\partial \eta}{\partial T}+\left(\frac{\partial g_{i j}}{\partial T}\right)_{\eta=c o n s t}
$$

With

$$
\left(\frac{\partial g_{i j}}{\partial T}\right)_{\eta=c o n s t}=\sum_{p=0}^{4} \sum_{q=1}^{4} a_{p q}\left(\beta \varepsilon_{i j}\right)^{p} \times\left(-\frac{p}{T}\right) \times \frac{\eta^{q-1}}{(1-\eta)^{q}}
$$

Second derivative of $\mathrm{g}(\mathrm{r})$ as a function of $\mathrm{T}$ 


$$
\begin{aligned}
\frac{\partial^{2} g_{i j}}{\partial T^{2}}=\frac{\partial^{2} g_{i j}}{\partial \eta^{2}} & \times \frac{\partial \eta}{\partial T} \times \frac{\partial \eta}{\partial T}+\left(\frac{\partial\left(\frac{\partial g_{i j}}{\partial \eta}\right)}{\partial T}\right)_{\eta=c o n s t} \times \frac{\partial \eta}{\partial T}+\left(\frac{\partial^{2} g_{i j}}{\partial T^{2}}\right)_{\eta=c o n s t}+\frac{\partial g_{i j}}{\partial \eta} \\
& \times \frac{\partial^{2} \eta}{\partial T^{2}}(C .22)
\end{aligned}
$$

Where

$$
\begin{gathered}
\left(\frac{\partial^{2} g_{i j}}{\partial T^{2}}\right)_{\eta=c o n s t}=\sum_{p=0}^{4} \sum_{q=1}^{4} a_{p q}\left(\beta \varepsilon_{i j}\right)^{p} \times \frac{p(p+1)}{T^{2}} \times \frac{\eta^{q-1}}{(1-\eta)^{q}} \\
\left(\frac{\partial\left(\frac{\partial g_{i j}}{\partial \eta}\right)}{\partial T}\right)_{\eta=c o n s t}=-\sum_{i=0}^{4} \sum_{j=1}^{4} \frac{p}{T} a_{p q}\left(\beta \varepsilon_{i j}\right)^{p} \frac{\eta^{q-2}}{(1-\eta)^{q+1}}(\eta+q-1)
\end{gathered}
$$

First derivative of $g(r)$ as a function of $n_{i}$

$$
\frac{\partial g_{i j}}{\partial n_{i}}=\frac{\partial g_{i j}}{\partial \eta} \times \frac{\partial \eta}{\partial n_{i}}
$$

Second derivate of $g(r)$ in function of $n_{i}$ and $n_{j}$ :

$$
\frac{\partial^{2} g_{i j}}{\partial n_{i} \partial n_{j}}=\frac{\partial^{2} g_{i j}}{\partial \eta^{2}} \times \frac{\partial \eta}{\partial n_{j}} \times \frac{\partial \eta}{\partial n_{i}}+\frac{\partial g_{i j}}{\partial \eta} \times \frac{\partial^{2} \eta}{\partial n_{i} \partial n_{j}}
$$

Second derivative of $g(r)$ as function of $V$ and $n_{i}$

$$
\frac{\partial^{2} g_{i j}}{\partial V \partial n_{i}}=\frac{\partial\left(\frac{\partial g}{\partial \eta}\right)}{\partial \eta} \times \frac{\partial \eta}{\partial n_{i}} \times \frac{\partial \eta}{\partial V}+\frac{\partial g}{\partial \eta} \times \frac{\partial^{2} \eta}{\partial V \partial n_{i}}=\frac{\partial^{2} g}{\partial \eta^{2}} \times \frac{\partial \eta}{\partial n_{i}} \times \frac{\partial \eta}{\partial V}+\frac{\partial g}{\partial \eta} \times \frac{\partial^{2} \eta}{\partial V \partial n_{i}}(C .27)
$$

Second derivative of $g(r)$ as a function of $T$ and $n_{i}$ 


$$
\begin{array}{r}
\frac{\partial^{2} g_{i j}}{\partial T \partial n_{i}}=\frac{\partial\left(\frac{\partial g_{i j}}{\partial \eta}\right)}{\partial \eta} \times \frac{\partial \eta}{\partial n_{i}} \times \frac{\partial \eta}{\partial T}+\frac{\partial g_{i j}}{\partial \eta} \times \frac{\partial^{2} \eta}{\partial T \partial n_{i}}+\frac{\partial\left(\frac{\partial g_{i j}}{\partial T}\right)_{\eta=c o n s t}}{\partial \eta} \times \frac{\partial \eta}{\partial n_{i}} \\
=\frac{\partial^{2} g_{i j}}{\partial \eta^{2}} \times \frac{\partial \eta}{\partial n_{i}} \times \frac{\partial \eta}{\partial T}+\frac{\partial g_{i j}}{\partial \eta} \times \frac{\partial^{2} \eta}{\partial T \partial n_{i}}+\frac{\partial\left(\frac{\partial g_{i j}}{\partial T}\right)_{\eta=c o n s t}}{\partial \eta} \times \frac{\partial \eta}{\partial n_{i}}
\end{array}
$$

$>\quad$ Second derivative of $\mathrm{g}(\mathrm{r})$ as a function of $\mathrm{T}$ and $\mathrm{V}$

$$
\frac{\partial^{2} g_{i j}}{\partial T \partial V}==\frac{\partial^{2} g_{i j}}{\partial \eta^{2}} \times \frac{\partial \eta}{\partial V} \times \frac{\partial \eta}{\partial T}+\frac{\partial g_{i j}}{\partial \eta} \times \frac{\partial^{2} \eta}{\partial T \partial V}+\frac{\partial\left(\frac{\partial g_{i j}}{\partial T}\right)_{\eta=c o n s t}}{\partial \eta} \times \frac{\partial \eta}{\partial V}
$$

After obtaining the derives of $\mathrm{g}_{\mathrm{ij}}$, we continue derivative for the radial distribution function for chains

$>\quad$ First derivative of $g_{i j}^{r e f}$ as a function of $\mathrm{V}$

$$
\begin{aligned}
& \frac{\partial g_{i j}^{r e f}}{\partial V} \\
& =\frac{4 \frac{\partial g_{D, D}}{\partial V}+\left(m_{i}+m_{j}-4\right)\left(3 \frac{\partial g_{D, D}}{\partial V}-\frac{\partial g_{S, S}}{\partial V}\right)+\left(m_{j}-2\right)\left(m_{i}-2\right)\left(2 \frac{\partial g_{D, D}}{\partial V}-\frac{\partial g_{S, S}}{\partial V}\right)}{m_{i} m_{j}}
\end{aligned}
$$

$>\quad$ Second derivative of $g_{i j}^{r e f}$ as a function of $\mathrm{V}$

$$
\begin{aligned}
& \frac{\partial^{2} g_{i j}^{r e f}}{\partial V^{2}} \\
& =\frac{4 \frac{\partial^{2} g_{D, D}}{\partial V^{2}}+\left(m_{i}+m_{j}-4\right)\left(3 \frac{\partial^{2} g_{D, D}}{\partial V^{2}}-\frac{\partial^{2} g_{S, S}}{\partial V^{2}}\right)+\left(m_{j}-2\right)\left(m_{i}-2\right)\left(2 \frac{\partial^{2} g_{D, D}}{\partial V^{2}}-\frac{\partial^{2} g_{S, S}}{\partial V^{2}}\right)}{m_{i} m_{j}}
\end{aligned}
$$

First derivative of $g_{i j}^{r e f}$ as a function of T 


$$
\begin{aligned}
& \frac{\partial g_{i j}^{r e f}}{\partial T} \\
& =\frac{4 \frac{\partial g_{D, D}}{\partial T}+\left(m_{i}+m_{j}-4\right)\left(3 \frac{\partial g_{D, D}}{\partial T}-\frac{\partial g_{S, S}}{\partial T}\right)+\left(m_{j}-2\right)\left(m_{i}-2\right)\left(2 \frac{\partial g_{D, D}}{\partial T}-\frac{\partial g_{S, S}}{\partial T}\right)}{m_{i} m_{j}}
\end{aligned}
$$

Second derivative of $g_{i j}^{r e f}$ as a function of T

$$
\begin{aligned}
& \frac{\partial^{2} g_{i j}^{r e f}}{\partial T^{2}} \\
& =\frac{4 \frac{\partial^{2} g_{D, D}}{\partial T^{2}}+\left(m_{i}+m_{j}-4\right)\left(3 \frac{\partial^{2} g_{D, D}}{\partial T^{2}}-\frac{\partial^{2} g_{S, S}}{\partial T^{2}}\right)+\left(m_{j}-2\right)\left(m_{i}-2\right)\left(2 \frac{\partial^{2} g_{D, D}}{\partial T^{2}}-\frac{\partial^{2} g_{S, S}}{\partial T^{2}}\right)}{m_{i} m_{j}}
\end{aligned}
$$

$>\quad$ First derivative of $g_{i j}^{r e f}$ as a function of $\mathrm{n}_{\mathrm{i}}$

$$
\begin{aligned}
& \frac{\partial g_{i j}^{r e f}}{\partial n_{i}} \\
& =\frac{4 \frac{\partial g_{D, D}}{\partial n_{i}}+\left(m_{i}+m_{j}-4\right)\left(3 \frac{\partial g_{D, D}}{\partial n_{i}}-\frac{\partial g_{S, S}}{\partial n_{i}}\right)+\left(m_{j}-2\right)\left(m_{i}-2\right)\left(2 \frac{\partial g_{D, D}}{\partial n_{i}}-\frac{\partial g_{S, S}}{\partial n_{i}}\right)}{m_{i} m_{j}}
\end{aligned}
$$

$>$ Second derivative of $g_{i j}^{r e f}$ as a function of $\mathrm{n}_{\mathrm{i}}$ and $\mathrm{n}_{\mathrm{j}}$

$$
\begin{aligned}
& \frac{\partial^{2} g_{i j}^{r e f}}{\partial n_{i} \partial n_{j}} \\
& =\frac{4 \frac{\partial^{2} g_{D, D}}{\partial n_{i} \partial n_{j}}+\left(m_{i}+m_{j}-4\right)\left(3 \frac{\partial^{2} g_{D, D}}{\partial n_{i} \partial n_{j}}-\frac{\partial^{2} g_{S, S}}{\partial n_{i} \partial n_{j}}\right)+\left(m_{j}-2\right)\left(m_{i}-2\right)\left(2 \frac{\partial^{2} g_{D, D}}{\partial n_{i} \partial n_{j}}-\frac{\partial^{2} g_{S, S}}{\partial n_{i} \partial n_{j}}\right)}{m_{i} m_{j}}
\end{aligned}
$$

$>\quad$ Second derivative of $g_{i j}^{r e f}$ as a function of $\mathrm{V}$ and $\mathrm{n}_{\mathrm{i}}$

$$
\begin{aligned}
& \frac{\partial^{2} g_{i j}^{r e f}}{\partial V \partial N_{i}} \\
& =\frac{4 \frac{\partial^{2} g_{D, D}}{\partial V \partial n_{i}}+\left(m_{i}+m_{j}-4\right)\left(3 \frac{\partial^{2} g_{D, D}}{\partial V \partial n_{i}}-\frac{\partial^{2} g_{S, S}}{\partial V \partial n_{i}}\right)+\left(m_{j}-2\right)\left(m_{i}-2\right)\left(2 \frac{\partial^{2} g_{D, D}}{\partial V \partial n_{i}}-\frac{\partial^{2} g_{S, S}}{\partial V \partial n_{i}}\right)}{m_{i} m_{j}}
\end{aligned}
$$


Second derivative of $g_{i j}^{r e f}$ as a function of $\mathrm{T}$ and $\mathrm{n}_{\mathrm{i}}$

$$
\begin{aligned}
& \frac{\partial^{2} g_{i j}^{r e f}}{\partial T \partial n_{i}} \\
& =\frac{4 \frac{\partial^{2} g_{D, D}}{\partial T \partial n_{i}}+\left(m_{i}+m_{j}-4\right)\left(3 \frac{\partial^{2} g_{D, D}}{\partial T \partial n_{i}}-\frac{\partial^{2} g_{S, S}}{\partial T \partial n_{i}}\right)+\left(m_{j}-2\right)\left(m_{i}-2\right)\left(2 \frac{\partial^{2} g_{D, D}}{\partial T \partial n_{i}}-\frac{\partial^{2} g_{S, S}}{\partial T \partial n_{i}}\right)}{m_{i} m_{j}}
\end{aligned}
$$

$>\quad$ Second derivative of $g_{i j}^{r e f}$ as a function of T and V

$$
\begin{aligned}
& \frac{\partial^{2} g_{i j}^{r e f}}{\partial T \partial V} \\
& =\frac{4 \frac{\partial^{2} g_{D, D}}{\partial T \partial V}+\left(m_{i}+m_{j}-4\right)\left(3 \frac{\partial^{2} g_{D, D}}{\partial T \partial V}-\frac{\partial^{2} g_{S, S}}{\partial T \partial V}\right)+\left(m_{j}-2\right)\left(m_{i}-2\right)\left(2 \frac{\partial^{2} g_{D, D}}{\partial T \partial V}-\frac{\partial^{2} g_{S, S}}{\partial T \partial V}\right)}{m_{i} m_{j}}
\end{aligned}
$$

Now we have the derivatives of $F$ :

$>$ First derivative of $\mathrm{F}$ as a function of $\mathrm{V}$

$$
\frac{\partial F}{\partial V}=2 \pi \times N_{A v} \times\left(\frac{N}{V} \times \text { doubleSommedv }-\frac{N}{V^{2}} \times \text { doubleSomme0 }\right)
$$

With

$$
\begin{array}{r}
\text { doubleSomme0 }=-\sum_{i} \sum_{j} m_{i} n_{i} m_{j} n_{j} \times d_{i j}^{3} l_{i j} g_{i j} \\
\text { doubleSommedv }=-\sum_{i} \sum_{j} m_{i} n_{i} m_{j} n_{j} \times d_{i j}^{3} l_{i j} \frac{\partial g_{i j}}{\partial V}
\end{array}
$$

Second derivative of $\mathrm{F}$ as a function of $\mathrm{V}$ 


$$
\begin{aligned}
\frac{\partial^{2} F}{\partial V^{2}}=2 \pi N_{A v} & \\
& \times\left(\frac{2}{V^{3}} \text { doubleSomme0 }-\frac{2}{V^{2}} \text { doubleSommed } v+\frac{1}{V}\right. \\
& \left.\times \sum_{i} \sum_{j} m_{i} n_{i} m_{j} n_{j} \times d_{i j}^{3} l_{i j} \frac{\partial^{2} g_{i j}}{\partial V^{2}}\right)(C .42)
\end{aligned}
$$

$>\quad$ First derivative of $\mathrm{F}$ as a function of $\mathrm{T}$

$$
\frac{\partial F}{\partial T}=-2 \pi \frac{N_{A v}}{V} \times \sum_{i} \sum_{j} m_{i} n_{i} m_{j} n_{j} l_{i j}\left(d_{i j}^{3} \frac{\partial g_{i j}}{\partial T}+3 d_{i j}^{2} \frac{\partial d_{i j}}{\partial T} g_{i j}\right)
$$

Where

$$
\frac{\partial g_{i j}}{\partial T}=-\sum_{i} \sum_{j} m_{i} n_{i} m_{j} n_{j} \times 3 d_{i j}^{2} \frac{\partial d_{i j}}{\partial T} l_{i j} g_{i j}-\sum_{i} \sum_{j} m_{i} n_{i} m_{j} n_{j} \times d_{i j}^{3} l_{i j} \frac{\partial g_{i j}}{\partial T}
$$

$>\quad$ Second derivative of $\mathrm{F}$ as a function of $\mathrm{T}$

$$
\begin{aligned}
\frac{\partial^{2} F}{\partial T^{2}}=\frac{\partial\left(\frac{\partial F}{\partial T}\right)}{\partial T} & =-2 \pi \frac{N_{A v}}{V} \sum_{i} \sum_{j} m_{i} n_{i} m_{j} n_{j} l_{i j}\left(3 d_{i j}^{2} \frac{\partial d_{i j}}{\partial T} \frac{\partial g_{i j}}{\partial T}+d_{i j}^{3} \frac{\partial^{2} g_{i j}}{\partial T^{2}}\right. \\
& \left.+6 d_{i j}\left(\frac{\partial d_{i j}}{\partial T}\right)^{2} g_{i j}+3 d_{i j}^{2} \frac{\partial^{2} d_{i j}}{\partial T^{2}} g_{i j}+3 d_{i j}^{2} \frac{\partial d_{i j}}{\partial T} \frac{\partial g_{i j}}{\partial T}\right)
\end{aligned}
$$

$>\quad$ First derivative of $F$ as a function of $n_{i}$ :

$$
\frac{\partial F}{\partial n_{l}}=-2 \pi \times \frac{N_{A v}}{V} \times \frac{\partial}{\partial n_{l}}\left(\sum_{i} \sum_{j} m_{i} n_{i} m_{j} n_{j} l_{i j} d_{i j}^{3} g_{i j}\right)
$$


Where

$$
\begin{aligned}
\frac{\partial}{\partial n_{l}}\left(\sum_{i} \sum_{j} m_{i} n_{i} m_{j} n_{j} l_{i j} d_{i j}^{3} g_{i j}\right) \\
=\sum_{i} \sum_{j} m_{i} n_{i} m_{j} n_{j} l_{i j} d_{i j}^{3} \frac{\partial g_{i j}}{\partial n_{l}}+\sum_{i} m_{i} n_{i} m_{l} l_{i l} d_{i l}^{3} g_{i l}+\sum_{j} m_{l} m_{j} n_{j} l_{l j} d_{l j}^{3} g_{l j} \\
=\sum_{i} \sum_{j} m_{i} n_{i} m_{j} n_{j} l_{i j} d_{i j}^{3} \frac{\partial g_{i j}}{\partial n_{l}}+2 \times \sum_{i} m_{i} n_{i} m_{l} l_{i j} d_{i j}^{3} g_{i l}
\end{aligned}
$$

Second derivative of $\mathrm{F}$ as a function of $\mathrm{n}_{\mathrm{i}}$ and $\mathrm{n}_{\mathrm{j}}$

$$
\frac{\partial^{2} F}{\partial n_{l} \partial n_{k}}=-2 \pi \times \frac{N_{A v}}{V} \times \frac{\partial^{2}}{\partial n_{l} \partial n_{k}}\left(\sum_{i} \sum_{j} m_{i} n_{i} m_{j} n_{j} l_{i j} d_{i j}^{3} g_{i j}\right)
$$

Where

$$
\begin{aligned}
\frac{\partial^{2}}{\partial n_{l} \partial n_{k}}\left(\sum_{i} \sum_{j} m_{i} n_{i} m_{j} n_{j} l_{i j} d_{i j}^{3} g_{i j}\right) \\
=2 \times l_{i j} d_{i j}^{3} \times\left(\sum_{i, j=k} m_{i} n_{i} m_{k} \frac{\partial g_{i l}}{\partial n_{k}}+\sum_{j, i=k} m_{i} n_{i} m_{l} \frac{\partial g_{k i}}{\partial n_{l}}\right)+2 \\
\times l_{i j} d_{i j}^{3} m_{k} m_{l} g_{k l}+\sum_{i} \sum_{j} m_{i} n_{i} m_{j} n_{j} l_{i j} d_{i j}^{3} \frac{\partial^{2} g_{i j}}{\partial n_{l} \partial n_{k}}
\end{aligned}
$$

$>\quad$ Second derivative of $\mathrm{F}$ as a function of $\mathrm{V}$ and $\mathrm{n}_{\mathrm{i}}$

$$
\begin{array}{r}
\frac{\partial^{2} F}{\partial V \partial n_{l}}=2 \pi N_{A v}\left(\frac{\partial}{\partial n_{l}}\left(-\frac{N}{V} \times \sum_{i} \sum_{j} m_{i} n_{i} m_{j} n_{j} \times d_{i j}^{3} l_{i j} \frac{\partial g_{i j}}{\partial V}\right)\right. \\
\left.+\frac{\partial}{\partial n_{l}}\left(-\frac{N}{V^{2}} \times \sum_{i} \sum_{j} m_{i} n_{i} m_{j} n_{j} \times d_{i j}^{3} l_{i j} g_{i j}\right)\right)
\end{array}
$$


Where

$$
\begin{aligned}
\frac{\partial}{\partial n_{l}}\left(-\frac{N}{V} \sum_{i} \sum_{j} m_{i} n_{i} m_{j} n_{j} \times d_{i j}^{3} l_{i j} \frac{\partial g_{i j}}{\partial V}\right) & \\
= & -\frac{N}{V} \sum_{i} \sum_{j} m_{i} n_{i} m_{j} n_{j} l_{i j} d_{i j}^{3} \frac{\partial^{2} g_{i j}}{\partial V \partial n_{l}}-\frac{2 N}{V} \sum_{i} m_{i} n_{i} m_{l} l_{i j} d_{i j}^{3} \frac{\partial g_{i j}}{\partial V} \\
& -\frac{1}{N} \sum_{i} \sum_{j} m_{i} n_{i} m_{j} n_{j} \times d_{i j}^{3} l_{i j} \frac{\partial g_{i j}}{\partial V}
\end{aligned}
$$

And

$$
\begin{aligned}
\frac{\partial}{\partial n_{l}}\left(-\frac{N}{V^{2}} \sum_{i} \sum_{j} m_{i} n_{i} m_{j} n_{j} \times d_{i j}^{3} l_{i j} g_{i j}\right) & \\
= & -\frac{N}{V^{2}} \sum_{i} \sum_{j} m_{i} n_{i} m_{j} n_{j} l_{i j} d_{i j}^{3} \frac{\partial g_{i j}}{\partial n_{l}}-\frac{2 N}{V^{2}} \sum_{i} m_{i} n_{i} m_{l} l_{i j} d_{i j}^{3} g_{i l} \\
& -\frac{1}{V^{2}} \sum_{i} \sum_{j} m_{i} n_{i} m_{j} n_{j} \times d_{i j}^{3} l_{i j} g_{i j}
\end{aligned}
$$

Second derivative of $\mathrm{F}$ as a function of $\mathrm{T}$ and $\mathrm{n}_{\mathrm{i}}$

$$
\begin{aligned}
\frac{\partial^{2} F}{\partial T \partial n_{l}}=-2 \pi & \frac{N_{A v}}{V}\left[\frac{\partial}{\partial n_{l}}\left(\sum_{i} \sum_{j} m_{i} n_{i} m_{j} n_{j} l_{i j} d_{i j}^{3} \frac{\partial g_{i j}}{\partial T}\right)\right. \\
& \left.+3 \frac{\partial}{\partial n_{l}}\left(\sum_{i} \sum_{j} m_{i} n_{i} m_{j} n_{j} l_{i j} d_{i j}^{2} \frac{\partial d_{i j}}{\partial T} g_{i j}\right)\right]
\end{aligned}
$$

With

$$
\begin{aligned}
\frac{\partial}{\partial n_{l}}\left(\sum_{i} \sum_{j} m_{i} n_{i} m_{j} n_{j} l_{i j} d_{i j}^{3} \frac{\partial g_{i j}}{\partial T}\right) \\
=\sum_{i} \sum_{j} m_{i} n_{i} m_{j} n_{j} l_{i j} d_{i j}^{3} \frac{\partial^{2} g_{i j}}{\partial T \partial n_{l}}+2 \times \sum_{i} m_{i} n_{i} m_{l} l_{i j} d_{i j}^{3} \frac{\partial g_{i j}}{\partial T}
\end{aligned}
$$


And

$$
\begin{aligned}
\frac{\partial}{\partial n_{l}}\left(\sum_{i} \sum_{j} m_{i} n_{i} m_{j} n_{j} l_{i j} d_{i j}^{2} \frac{\partial d_{i j}}{\partial T} g_{i j}\right) \\
=\sum_{i} \sum_{j} m_{i} n_{i} m_{j} n_{j} l_{i j} d_{i j}^{2} \frac{\partial d_{i j}}{\partial T} \frac{\partial g_{i j}}{\partial n_{l}}+2 \times \sum_{i} m_{i} n_{i} m_{l} l_{i j} d_{i j}^{2} \frac{\partial d_{i j}}{\partial T} g_{i j}(C .55)
\end{aligned}
$$

$>\quad$ Second derivative of $\mathrm{F}$ as a function of $\mathrm{T}$ and $\mathrm{V}$

$$
\begin{aligned}
\frac{\partial^{2} F}{\partial T \partial V}=-2 \pi & \times\left[\frac{\partial}{\partial V}\left(\frac{N_{A v}}{V} \sum_{i} \sum_{j} m_{i} n_{i} m_{j} n_{j} l_{i j} d_{i j}^{3} \frac{\partial g_{i j}}{\partial T}\right)\right. \\
& \left.+3 \frac{\partial}{\partial V}\left(\frac{N_{A v}}{V} \sum_{i} \sum_{j} m_{i} n_{i} m_{j} n_{j} l_{i j} d_{i j}^{2} \frac{\partial d_{i j}}{\partial T} g_{i j}\right)\right]
\end{aligned}
$$

Where

$$
\begin{aligned}
\frac{\partial}{\partial V}\left(\frac{N_{A v}}{V} \sum_{i} \sum_{j} m_{i} n_{i} m_{j} n_{j} l_{i j} d_{i j}^{3} \frac{\partial g_{i j}}{\partial T}\right) \\
=-\frac{N_{A v}}{V^{2}} \sum_{i} \sum_{j} m_{i} n_{i} m_{j} n_{j} l_{i j} d_{i j}^{3} \frac{\partial g_{i j}}{\partial T} \\
+\frac{N_{A v}}{V} \sum_{i} \sum_{j} m_{i} n_{i} m_{j} n_{j} l_{i j} d_{i j}^{3} \frac{\partial^{2} g_{i j}}{\partial T \partial V}
\end{aligned}
$$

And

$$
\begin{aligned}
\frac{\partial}{\partial V}\left(\frac{N_{A v}}{V} \sum_{i} \sum_{j} m_{i} n_{i} m_{j} n_{j} l_{i j} d_{i j}^{2} \frac{\partial d_{i j}}{\partial T} g_{i j}\right) \\
=-\frac{N_{A v}}{V^{2}} \sum_{i} \sum_{j} m_{i} n_{i} m_{j} n_{j} l_{i j} d_{i j}^{2} \frac{\partial d_{i j}}{\partial T} g_{i j} \\
+\frac{N_{A v}}{V} \sum_{i} \sum_{j} m_{i} n_{i} m_{j} n_{j} l_{i j} d_{i j}^{2} \frac{\partial d_{i j}}{\partial T} \frac{\partial g_{i j}}{\partial V}
\end{aligned}
$$


Appendix D: The values of $a_{p q}$ and $b_{p q}$ in equation (31) and (32) at contact and at $\lambda=1.5$

Table D.1: Values of $\mathrm{a}_{\mathrm{pq}}$ at contact

\begin{tabular}{|r|r|r|r|r|}
\hline \multicolumn{7}{|l|}{$\mathbf{a}_{\mathbf{p q}}$} & \multicolumn{5}{|c|}{ q } \\
\hline $\mathbf{p}$ & $\mathbf{1}$ & $\mathbf{2}$ & $\mathbf{3}$ & $\mathbf{4}$ \\
\hline & 1 & 1.5 & 0.5 & 0 \\
\hline $\mathbf{0}$ & 0.796 & -2.774 & 0.929 & -0.441 \\
\hline $\mathbf{1}$ & 1.211 & -21.738 & 49.269 & -21.245 \\
\hline $\mathbf{2}$ & -0.194 & 37.165 & -100.66 & 50.837 \\
\hline $\mathbf{4}$ & 0 & -23.186 & 68.17 & -37.694 \\
\hline
\end{tabular}

Table D.2 : Values of $b_{\mathrm{pq}}$ at contact

\begin{tabular}{|r|r|r|r|r|}
\hline \multicolumn{1}{|l|}{$\mathbf{b}_{\mathbf{p q}}$} & \multicolumn{5}{|c|}{$\mathbf{9}$} \\
\hline $\mathbf{p}$ & $\mathbf{1}$ & $\mathbf{2}$ & $\mathbf{3}$ & $\mathbf{4}$ \\
\hline & 0.539 & 1.122 & 0.849 & -0.28 \\
\hline $\mathbf{0}$ & 0.362 & 0.695 & -6.602 & 6.341 \\
\hline $\mathbf{1}$ & 6.646 & -39.522 & 71.354 & -42.271 \\
\hline $\mathbf{2}$ & -14.254 & 76.477 & -126.845 & 70.255 \\
\hline $\mathbf{3}$ & 14.751 & -65.946 & 92.625 & -43.548 \\
\hline $\mathbf{4}$ & & & & \\
\hline
\end{tabular}

Table D.3 : Values of $\mathrm{a}_{\mathrm{pq}}$ at $\lambda=1.5$

\begin{tabular}{|c|c|c|c|c|}
\hline \multirow{3}{*}{$\begin{array}{l}a_{p q} \\
p\end{array}$} & \multicolumn{4}{|c|}{$\mathbf{q}$} \\
\hline & & & & \\
\hline & 1 & 2 & 3 & 4 \\
\hline $\mathbf{0}$ & 0,39971235 & $-0,253303103$ & $-0,90766587$ & 0,36773252 \\
\hline 1 & 2,23090715 & $-0,814209759$ & $-1,5151413$ & 1,85997259 \\
\hline 2 & 1,23339104 & $-19,75524069$ & 45,417694 & $-22,7662545$ \\
\hline 3 & $-1,26689783$ & 38,72263605 & $-102,966537$ & 50,5019509 \\
\hline 4 & $-1,46680101$ & $-21,99486901$ & 68,2862575 & $-33,7783636$ \\
\hline
\end{tabular}


Table D.4 : Values of $b_{p q}$ at $\lambda=1.5$

\begin{tabular}{|c|c|c|c|c|}
\hline \multirow{3}{*}{$\begin{array}{l}\sigma_{p q} \\
p\end{array}$} & \multicolumn{4}{|c|}{$\mathbf{q}$} \\
\hline & & & & \\
\hline & 1 & 2 & 3 & 4 \\
\hline $\mathbf{0}$ & 0,99976794 & $-0,619769592$ & $-0,11246443$ & $-0,15939359$ \\
\hline 1 & 0,07548764 & 3,068742688 & $-9,23475302$ & 9,21151101 \\
\hline 2 & 6,12672467 & $-36,52181926$ & 66,3940585 & $-43,9966187$ \\
\hline 3 & $-14,7504035$ & 79,28258946 & $-130,880088$ & 70,5244228 \\
\hline 4 & 14,3442077 & $-63,52369801$ & 90,7216739 & $-39,4943939$ \\
\hline
\end{tabular}

